\title{
Identified GABAergic and Glutamatergic Neurons in the Mouse Inferior Colliculus Share Similar Response Properties
}

\author{
Munenori Ono, ${ }^{1,2}$ Deborah C. Bishop, ${ }^{1}$ and $\odot$ Douglas L. Oliver ${ }^{1}$ \\ ${ }^{1}$ Department of Neuroscience, University of Connecticut Health Center, Farmington, Connecticut 06030-3401, and ${ }^{2}$ Department of Physiology, Kanazawa \\ Medical University, Ishikawa 920-0293, Japan
}

GABAergic neurons in the inferior colliculus (IC) play a critical role in auditory information processing, yet their responses to sound are unknown. Here, we used optogenetic methods to characterize the response properties of GABAergic and presumed glutamatergic neurons to sound in the IC. We found that responses to pure tones of both inhibitory and excitatory classes of neurons were similar in their thresholds, response latencies, rate-level functions, and frequency tuning, but GABAergic neurons may have higher spontaneous firing rates. In contrast to their responses to pure tones, the inhibitory and excitatory neurons differed in their ability to follow amplitude modulations. The responses of both cell classes were affected by their location regardless of the cell type, especially in terms of their frequency tuning. These results show that the synaptic domain, a unique organization of local neural circuits in the IC, may interact with all types of neurons to produce their ultimate response to sound.

Key words: GABAergic neuron; inferior colliculus; optogenetics

Significance Statement

Although the inferior colliculus (IC) in the auditory midbrain is composed of different types of neurons, little is known about how these specific types of neurons respond to sound. Here, for the first time, we characterized the response properties of GABAergic and glutamatergic neurons in the IC. Both classes of neurons had diverse response properties to tones but were overall similar, except for the spontaneous activity and their ability to follow amplitude-modulated sound. Both classes of neurons may compose a basic local circuit that is replicated throughout the IC. Within each local circuit, the inputs to the local circuit may have a greater influence in determining the response properties to sound than the specific neuron types.

\section{Introduction}

Inhibition plays a crucial role in computation in the brain. In the sensory pathway, it is known that the interaction of excitatory and inhibitory synaptic inputs shapes the neural information processing to sensory inputs (Wehr and Zador, 2003; Wu et al., 2006; Sato et al., 2016). Thus, it is essential to consider the excitatory and inhibitory components to explain the function of a neural circuit (van Vreeswijk and Sompolinsky, 1996; Carandini and Heeger, 2011; Carney et al., 2016).

The inferior colliculus (IC) is an obligatory auditory center in the midbrain where all the auditory information from parallel

\footnotetext{
Received March 14, 2017; revised July 19, 2017; accepted Aug. 5, 2017.

Author contributions: M.O. and D.L.O. designed research; M.O. and D.C.B. performed research; M.O., D.C.B., and D.L.O. analyzed data; M.O. and D.L.O. wrote the paper.

This work was supported by National Institutes of Health Grants R01 DC000189 and R21 DC013822, UConn Health Center Research Advisory Council Grant 401139UCHC, Japan Society for the Promotion of Science KAKENHI Grant JP16K11200, and Grant for Promoted Research from Kanazawa Medical University S2016-8. We thank Drs. Shigeyuki Kuwada, Duck Kim, and Monty Escabí for helpful advice on data analysis.

The authors declare no competing financial interests.

Correspondence should be addressed to Dr. Munenori Ono, Department of Physiology, Kanazawa Medical University, Ishikawa 920-0293, Japan. E-mail: onomn@kanazawa-med.ac.jp.

DOI:10.1523/JNEUROSCI.0745-17.2017

Copyright $\odot 2017$ the authors $\quad 0270-6474 / 17 / 378952-13 \$ 15.00 / 0$
}

pathways in the brainstem is integrated and sent to the forebrain. In the IC, $\sim 25 \%$ of neurons are GABAergic (Oliver et al., 1994; Merchán et al., 2005; Ono et al., 2005), whereas all other neurons are glutamatergic. Virtually, all the IC neurons receive inhibitory inputs, and these strongly affect the responses to sound (Gittelman et al., 2009; Kuo and Wu, 2012; Li and Pollak, 2013; Xiong et al., 2013; Ono and Oliver, 2014a, b). Furthermore, the IC has a unique inhibitory neural circuit that includes several types of GABAergic neurons. One of these, a large-sized GABAergic neuron with dense axosomatic excitatory inputs, projects to the medial geniculate body (Ito et al., 2009). However, despite their importance (Pollak et al., 2011), it is unknown how any of types of GABAergic neurons in the IC respond to sound because the GABAergic neurons have never been identified in electrophysiological recordings in vivo.

Recently, using an optogenetics method, we successfully identified GABAergic neurons in the IC in vivo (Ono et al., 2016). We used VGAT-ChR2(H134R)-EYFP mice (Zhao et al., 2011) in which all inhibitory neurons (GABAergic and glycinergic neurons) specifically express channelrhodopsin-2. In this transgenic animal, a monochromatic laser-light stimulus of the IC from the brain surface evoked firing in GABAergic and inhibited firing in 
glutamatergic neurons (Ono et al., 2016). This method enabled us to efficiently isolate and separate the neural responses of GABAergic neurons from those of glutamatergic neurons in the IC.

In the present study, we used our optogenetic methods to test the response properties of both GABAergic and glutamatergic neurons to tones and amplitude-modulated (AM) sound. We found that both classes of neurons were heterogeneous with diverse response properties to sound. In the responses to tones, the population data from both cell classes showed no clear differences. In contrast, GABAergic and glutamatergic neurons did differ in their responses to AM sound. They also differed in their spontaneous firing rate. The response properties of both cell classes were affected by their location in the IC, in that nearby neurons shared similar frequency response areas (FRAs), regardless of the cell types. In addition, the maximum firing rates and the FRA's bandwidths (BWs) of both cell classes varied in subregions of the IC.

\section{Materials and Methods}

Ethical approval. All experiments were approved by the Animal Care and Use Committee at the University of Connecticut Health Center and done in accordance with institutional guidelines and with the National Institutes of Health Guide for the care and use of laboratory animals. All efforts were made to minimize the number of animals used and their suffering.

Animals. We used 88 transgenic mice (VGAT-mhChR2-YFP, $\mathrm{Tg}$ (Slc32a1COP $\left.4^{*} H 134 R / E Y F P\right) 8 G f n g / J ; \# 14548$, The Jackson Laboratory; VGATChR2 mice) of either sex (postnatal day 1.5-4 months). The breeding procedure was described previously (Ono et al., 2016).

Sound system. Acoustic stimuli were generated by a TDT System 3 (Tucker Davis Technologies) under the control of custom software (Brian Bishop, University of Connecticut Health Center, Farmington, CT) written in MATLAB (The MathWorks). All sounds were delivered by a closed system that included electrostatic speakers (Tucker Davis Technologies EC1) coupled to small metal tubes inserted into the external auditory meatus to minimize the acoustic crosstalk (Ono and Oliver, 2014b). The sound system was calibrated from 100 to $100,000 \mathrm{~Hz}$ by using a $1 / 4$ inch microphone (Type 4135 , Brüel \& Kjaer) at the end of the ear tubes.

Surgical preparation. VGAT-ChR2 mice were anesthetized with a mixture of ketamine $(100 \mathrm{mg} / \mathrm{kg})$, xylazine $(20 \mathrm{mg} / \mathrm{kg})$, and acepromazine $(10 \mathrm{mg} / \mathrm{kg})$, and maintained in an areflexive state with isoflurane $(0.5 \%-$ $1 \%)$ mixed with oxygen during the surgery and recording. Body temperature was monitored and maintained at $>35^{\circ} \mathrm{C}$ by a DC temperature controller (FHC). Vital signs also were monitored (MouseOx Plus, Starr Life Science), and the surgery and recordings were done in a doublewalled sound-attenuating chamber (IAC).

The surgical procedure was described previously (Ono and Oliver, 2014a, b). After the craniotomy, the auditory brainstem response (ABR) to a click $(0.5 \mathrm{~ms})$ was measured to verify normal hearing. The threshold of the $\mathrm{ABR}$ was $\sim 30 \mathrm{~dB}$ (left, $31.5 \pm 0.7 \mathrm{~dB}$, right, $30.9 \pm 0.7 \mathrm{~dB}, n=88$ ). Mice were used for experiments only when the ABR threshold was $<40 \mathrm{~dB}$.

Single-unit recordings with optogenetic identification of cell types. The procedure for the single-unit recordings with optogenetic cell type identification was described previously (Ono et al., 2016). Briefly, single-cell extracellular recordings were obtained using borosilicate glass pipettes filled with $0.01 \mathrm{~m}$ PBS, pH 7.4, with $2 \%$ Neurobiotin (4-7 M $\Omega$ ). After the single unit was isolated, we identified the cell type optogenetically. Light was generated by a blue laser (MBL-III-473 nm to $200 \mathrm{~mW}, \mathrm{CNI}$ ) and delivered through a $400-\mu \mathrm{m}$-diameter optical fiber whose tip was placed several millimeters above the brain surface. The light stimulus was a $10-50 \mathrm{~mW} / \mathrm{mm}^{2}$ light pulse at the fiber tip. In most experiments, a $30 \mathrm{~ms}$ light pulse was used, but in some experiments, a longer pulse up to 250 ms was used. Light pulses were given every $4 \mathrm{~s}$. Light-evoked firing in GABAergic neurons but suppressed spikes in other neurons. We judged that the neuron was suppressed when the light reduced sound evoked spikes by $>50 \%$. In the previous study (Ono et al., 2016), we also verified the validity of the optogenetic identification by immunohistochemical identification of GAD67.
The signals were amplified, bandpass filtered from 300 to $4000 \mathrm{~Hz}$, and sampled at $10 \mathrm{kHz}$ with a Multiclamp 700B Amplifier, Digidata 1440A digitizer and Clampex 10.2 system (Molecular Devices). The voltage signals were recorded in current-clamp mode. In parallel with recording the signals, the spike times were extracted using a window discriminator and recorded with the Tucker Davis Technologies System 3 and MATLAB software.

Acoustic stimuli. After the cell type identification, the neuron's best frequency $(\mathrm{BF})$ was determined by using $100 \mathrm{~ms}$ contralateral tone bursts at $70-80 \mathrm{~dB}$ ( $5 \mathrm{~ms}$ rise/fall). First, we presented the pure tones whose frequency ranged from 2 to $76.1 \mathrm{kHz}$ ( 0.25 octave step, 3 times) and then presented tones with smaller frequency steps within a narrow frequency range. We used $500 \mathrm{~Hz}$ or $1 \mathrm{kHz}$ steps when the $\mathrm{BF}$ was $<20$ or $>20 \mathrm{kHz}$, respectively. In many neurons, the characteristic frequency $(\mathrm{CF})$ and threshold also were determined by reducing the sound intensity $(5 \mathrm{~dB}$ step). BF was defined as the frequency where the neuron showed the strongest response. CF was defined as the frequency where the lowest sound level could evoke the response. At BF or CF, the sound intensity was varied from 0 to $80 \mathrm{~dB}$ ( $5 \mathrm{~dB}$ step) to obtain the rate-intensity function. The spike latency was measured as the shortest interval between the sound onset and the first spike in the responses to $0-80 \mathrm{~dB} B F$ or $\mathrm{CF}$ tones. Peristimulus time histograms (PSTHs) were obtained by presenting 100 or $200 \mathrm{~ms}$ CF tones 20 times (every $1 \mathrm{~s}$ ) that varied in sound intensity from 10 to $40 \mathrm{~dB}$ above threshold.

In some experiments, we also recorded the FRA and/or the responses to AM sound. The FRA was obtained from the pseudorandomly presented pure tones, which were presented to both ears, ipsilateral ear and contralateral ear sequentially (100 ms duration, $200 \mathrm{~ms}$ interval). The frequency was varied from 2 to $76.1 \mathrm{kHz}$ ( 0.25 octave step). The sound intensity was varied from 0 to $80 \mathrm{~dB}$. For $\mathrm{AM}$ sound, we used either a sinusoid or a raised sine modulation envelope (Bernstein and Trahiotis, 2010). To obtain the modulation transfer function, we used $60-70 \mathrm{~dB}$ $\mathrm{AM}$ one-octave noise ( $1 \mathrm{~s}$ every $2 \mathrm{~s}$, presented $2-4$ times) varying the modulation frequency from 2 to $512 \mathrm{~Hz}$ ( 1 octave steps). In some experiments, we measured the spike jitter and reliability by the shuffled correlogram method (Zheng and Escabí, 2008, 2013). To measure the spike jitter and reliability, we repeated the AM stimuli ( $2 \mathrm{~s}$ every $4 \mathrm{~s}) 10$ times for each modulation frequency.

Histology. The histological procedure was described previously (Ono et al., 2016). Briefly, after recording a single cell, the recording site was marked with Neurobiotin by current injection (200 nA, 50\% duty cycle of $500 \mathrm{~ms}, 5 \mathrm{~min}$ ). When the electrophysiological experiment was finished, animals were given additional anesthesia ( $200 \mathrm{mg} / \mathrm{kg}$ ketamine $/ 40$ $\mathrm{mg} / \mathrm{kg}$ xylazine $/ 20 \mathrm{mg} / \mathrm{kg}$ acepromazine) and were transcardially perfused with $0.01 \mathrm{~m}$ PBS, pH 7.4, followed by $4 \%$ PFA in $0.1 \mathrm{~m}$ buffer, $\mathrm{pH}$ 7.4. After dissection, brains were postfixed in $4 \%$ PFA and then stored in $30 \%$ sucrose solution.

To identify the recording location and subregions of the IC, we used the relative density of glycinergic and GABAergic axons. Brains were sectioned at $40 \mu \mathrm{m}$ and stained immunohistochemically. We used primary antibodies for GAD67 (mouse anti-GAD67, Millipore MAB5406, 1:3000) and GLYT2 (guinea pig anti-GLYT2 Millipore AB1773, 1:10,000). After washing, the sections were reacted with secondary antibodies and streptavidin (Invitrogen Streptavidin AlexaFluor-568, $1 \mathrm{mg} / \mathrm{ml}$ ). Secondary antibodies were AlexaFluor-488 goat anti-mouse (1:200) and AlexaFluor-647 goat anti-guinea pig (1:200). After staining, the sections were mounted, coverslipped, and imaged with a Zeiss Axiovert $200 \mathrm{M}$ microscope (Carl Zeiss). The presence of glycinergic axons defined the central nucleus of IC (ICC), where in area 1 GLYT2 > GAD67, in area 2 GAD67 > GLYT2, at the border where GLYT2 = GAD67, and in cortex of IC GLYT2 was absent. The recording locations were identified by the Streptavidin AlexaFluor-568 signals in the sections. When multiple neurons were recorded in an animal, the location of each neuron was based on the recording depth and the mediolateral and anteroposterior position of the neuron in the IC. We excluded the data when the correspondence between the recording depth and the labeled site was ambiguous.

Data analysis. Data were analyzed with Clampex 10.2 and MATLAB.

Spike shape. To analyze the spike shape of the recorded neurons, we extracted and averaged the spontaneous and/or sound-evoked spikes 
$>200$ times. The extracted spikes were aligned to the larger of peak or trough. Spike width was measured from $20 \%$ of the peak to $20 \%$ of the trough (Moore and Wehr, 2013).

Rate-level function analysis. To evaluate the monotonicity of the rate-level functions, we measured monotonicity index (MI). MI was calculated by dividing the response rate at 80 $\mathrm{dB}$ by the maximum response rate (Moore and Wehr, 2013). To analyze the response gain of the rate-level functions, we fit the rise phase of the function with a three parameter Gaussian and extracted the dynamic range for firing rate $(\Delta \mathrm{FR})$ and sound levels $(\Delta \mathrm{dB})$ from the fit (Watkins and Barbour, 2011; Moore and Wehr, 2013). The dynamic range for firing rate and sound level was measured as the difference of firing rate and sound level between $20 \%$ and $80 \%$ of the maximum response of the fitted curve, respectively. We also calculated the slope of the rising phase of the rate-level functions, dividing the $\Delta \mathrm{FR}$ by $\Delta \mathrm{dB}$. In contrast to the previous studies (Watkins and Barbour, 2011; Moore and Wehr, 2013), we fitted only the rise phase of the functions because we did not use fitting to analyze the falling phase. We only used the data fitted with $R^{2}>0.8$.

PSTH analysis. PSTH was constructed with a bin size of $5 \mathrm{~ms}$. The peak time of PSTH was measured as the time point that showed the largest binned response. The duration of PSTH was evaluated at the $20 \%$ width. To obtain the duration of the PSTH curve, we measured the first and the last time points that intersect the $20 \%$ of the PSTH peak. To evaluate the changes of the peak time and duration by sound intensity, we measured $\Delta$ peak time and $\Delta$ duration by subtracting the peak time or duration at 10 $\mathrm{dB}$ above threshold from the peak time or duration at $30 \mathrm{~dB}$ above threshold, respectively. In some closely located $(<350 \mu \mathrm{m})$ neuron pairs, we measured the correlation coefficient between their PSTHs. The correlation coefficient was measured using the response between 0 and $120 \mathrm{~ms}$ after the sound onset. We calculated the correlation coefficient of PSTHs only when the interval of CFs of the paired neurons was within 0.25 octave to rule out the effect of the difference in the stimulus frequencies.

FRA analysis. We used the highest firing rate in the FRA recording as the maximum firing rate of the recorded neuron. To evaluate the FRA shape, we measured the BW of the FRA at $10 \mathrm{~dB}$ (BW10) and $40 \mathrm{~dB}$ (BW40) above threshold. To measure the BWs, we calculated the centroid and the second moment about the centroid $\left(\sigma_{\mathrm{m}}\right)$ at each sound level (Escabí et al., 2007). In contrast to the original method by Escabí et al. (2007), we used the quadruple value of $\sigma_{\mathrm{m}}$ as BW: BW $=4 \sigma_{\mathrm{m}}$. When a neuron only responded significantly to one frequency tone at a certain sound level $\left(\sigma_{\mathrm{m}}=0\right)$, we set BW as 0.25 , the octave step value of our FRA recording. To compare the FRAs to contralateral and diotic tones, we measured the threshold shift, the BW index (BWI), and the binaural maximum firing rate ratio (BMR). The threshold shift was calculated by subtracting the threshold value to contralateral tones from that to diotic tones. BWI was calculated as follows:

$$
2 \times \mathrm{BW}_{\mathrm{dic}} /\left(\mathrm{BW}_{\mathrm{dic}}+\mathrm{BW}_{\text {contra }}\right)
$$

where $B W_{d i c}$ was $B W$ to diotic tones and $B W_{\text {contra }}$ was BW to contralateral tones. The BMR was calculated by dividing maximum firing rate in the diotic FRA by that in the contralateral FRA. For BWI and rate ratio, we classified them as decreased when they were $<0.75$, increased when they were $>1.25$, and no change when they were between 0.75 and 1.25. To evaluate the binaural facilitation or inhibition, we used BWI and BMR. We set a $25 \%$ change in rate or BW as a significant change and classified the neurons into five groups: No change, Decreased, Increased, BW increased-Rate decreased, Rate increased-BW decreased. We classified the neurons within the range indicated by $(0.75<$ BWI $<1.25) \times$ $(0.75<$ BMR $<1.25)$ as No change. Also, we classified the neurons within the range indicated by $(\mathrm{BWI}<1.25) \times(\mathrm{BMR}<1.25) \mid(0.75<$
B GABA

GLU
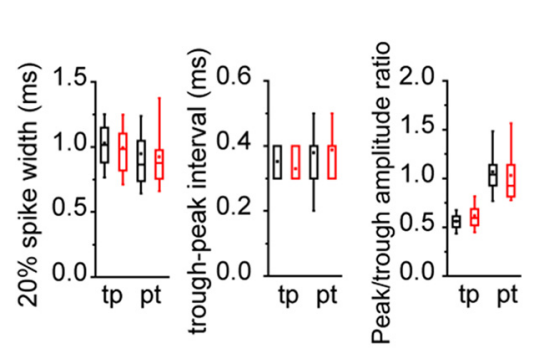

(1)

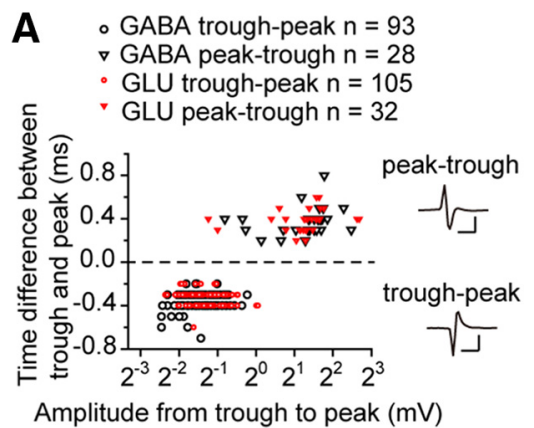

Figure 1. GABAergic and glutamatergic neurons in the IC had similar spike widths. $A$, The time difference between trough and was plotted against the spike amplitude. The positive time difference means that the peak preceded the trough and vice (inverted triangles), whereas the trour subsequent box plots, the box represents 25 th, 50 th, and 75 th percentiles. Whiskers represent 10 th and 90 th percentiles. Square value. tp, Trough-peak; pt, peak-trough.

BWI $<1.25) \times(0.75<$ BMR $<1.25)$ as Decreased and the neurons within the range indicated by $(0.75<\mathrm{BWI}) \times(0.75<\mathrm{BMR}) \mid(0.75<$ $\mathrm{BWI}<1.25) \times(0.75<\mathrm{BMR}<1.25)$ as Increased. The neurons within the range indicated by $(1.25 \leq \mathrm{BWI}) \times(\mathrm{BMR} \leq 0.75)$ were classified as BW increased-Rate decreased. Conversely, the neurons within the range indicated by $(\mathrm{BWI} \leq 0.75) \times(1.25 \leq \mathrm{BMR})$ were classified as Rate increased-BW decreased.

For closely located $(<350 \mu \mathrm{m})$ neuron pairs, we measured the correlation coefficient between the FRAs to contralateral tones. The correlation coefficient was calculated between the data matrices of the FRA using the "corrcoef" function in MATLAB. For CF and threshold analysis, we did not use the values from FRA recordings.

AM sound analysis. The rate modulation transfer function (rMTF) was constructed from the firing rate during the sound presentation excluding the onset component $(<100 \mathrm{~ms})$. The property of the rMTF was evaluated by their shape. First, we excluded from the shape evaluation the neurons with low maximum firing rate to AM sound $(<5 \mathrm{~Hz})$ from shape evaluation and classified them as low rate. For shape evaluation, we first normalized an rMTF by its maximum firing rate. Then, we set three boundaries $(0.25,0.5$, and 0.75$)$ and checked whether the normalized firing rate crossed the boundaries when the modulation frequency increased by an octave step. When the normalized firing rate crossed the lines in the upper or lower direction, we judged the change as UP or DOWN, respectively. When the normalized firing rate did not cross the lines, we classified it as STAY. If the rMTF showed only DOWN or STAY, we classified it as low pass. When the rMTF only showed UP or STAY, we classified it as high pass. We classified the RMTF as band reject when the rMTF showed a transition from the sequence of DOWN and STAY to that of UP and STAY only once. Conversely, when the rMTF showed a transition from UP to DOWN only one time, we classified it as bandpass. When rMTF had several transitions from UP to DOWN or DOWN to UP, we classified it as multipeak.

In addition to the rMTFs, the temporal modulation transfer function (tMTF) was also measured. Synchronization was assessed by Rayleigh test $(p<0.01)$. For this analysis, only the recordings, repeated four times, were used. Further, vector strength was measured to construct tMTF only when the response was significantly synchronized to the envelope. In some experiments, the spike jitter and reliability were measured using shuffled correlogram method (Zheng and Escabí, 2008, 2013).

Statistical analysis. The data from two groups were evaluated by the Wilcoxon signed-rank test. For multiple comparisons, we used an ANOVA that was only applied to the groups that satisfied the homogeneity of variance examined by the Bartlett test. For other groups, we used Kruskal-Wallis test. For pairwise comparison among multiple groups, we used the Tukey HSD test or the Steel-Dwass test. With some data, we calculated the correlation coefficient $(R)$, which was also statistically 
Table 1. The parameters of the spike shape

\begin{tabular}{llll}
\hline & GABAergic & Glutamatergic & $p$ \\
\hline Trough-peak spikes & $n=93$ & $n=105$ & \\
20\% width (ms) & $1.03 \pm 0.02$ & $0.99 \pm 0.03$ & 0.34 \\
Peak-trough interval (ms) & $0.35 \pm 0.01$ & $0.33 \pm 0.01$ & 0.28 \\
Peak/trough amplitude ratio & $0.56 \pm 0.01$ & $0.62 \pm 0.02$ & 0.07 \\
Peak-trough spikes & $n=28$ & $n=32$ & \\
20\% width (ms) & $0.95 \pm 0.07$ & $0.92 \pm 0.05$ & 1.0 \\
Peak-trough interval (ms) & $0.38 \pm 0.02$ & $0.39 \pm 0.02$ & 0.89 \\
Peak/trough amplitude ratio & $1.07 \pm 0.05$ & $1.03 \pm 0.06$ & 0.56 \\
\hline
\end{tabular}

A

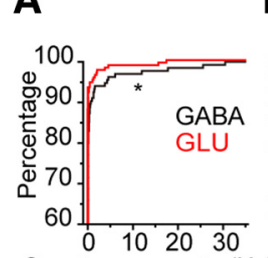

Spontaneous rate $(\mathrm{Hz})$

E

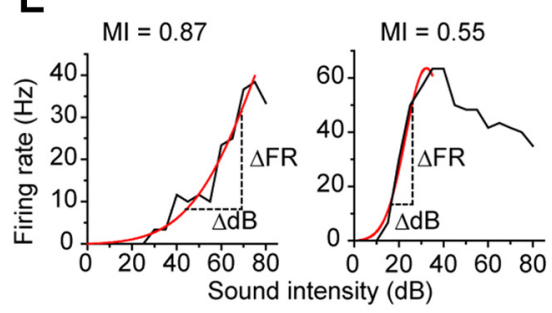

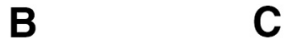

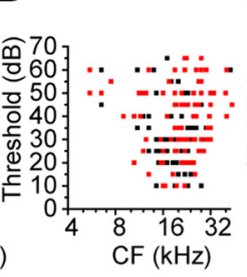

C

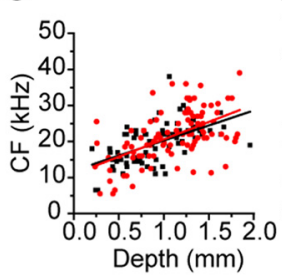

$\mathbf{F}$

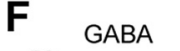

G

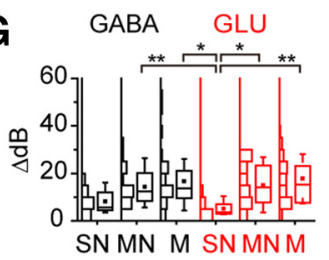

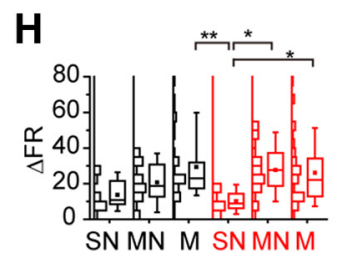

I

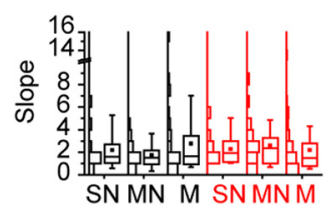

Figure 2. The spontaneous firing rates and the response to $C F$ tones of the GABAergic and glutamatergic neurons in the IC. $A$, The spontaneous firing rates of GABAergic (black) and glutamatergic (red) neurons were plotted by probabilistic curves. ${ }^{*} p<$ 0.05. $\boldsymbol{B}$, The threshold sound intensities of the GABAergic (black square) and glutamatergic (red squares) neurons plotted relative to the CFs. C, CF was plotted against the depth of the recording site. Black lines indicate the fitted line for the data of the GABAergic neurons. Red lines indicate the fitted line for the data of the glutamatergic neurons ( $y=11.92+0.0084 x$, and $y=10.97+$ $0.0096 x$ ). D, Spike latency was plotted against the depth of the recording site. Black lines indicate the fitted line for the data of the GABAergic neurons. Red lines indicate the fitted line for the data of the glutamatergic neurons ( $y=35.74-0.012 x$, and $y=$ $30.38-0.0096 x$ ). $E$, The examples of the RLFs. Both were recorded from GABAergic neurons. Left, Monotonic RLFs. Right, Nonmonotonic RLFs. Horizontal dotted lines indicate the $\Delta \mathrm{dB}$. Vertical dotted lines indicate the $\Delta F R$. $\boldsymbol{F}$, The histograms of Mls. Dotted lines indicate the border of monotonic (M), moderate nonmonotonic (NM), and strong nonmonotonic (SN). G-I, Box plots of $\Delta \mathrm{dB}(\boldsymbol{G}), \Delta \mathrm{FR}(\boldsymbol{H})$, and slope $(\boldsymbol{I})$. Boxplots were presented with histograms (left to boxplots). ${ }^{*} p<0.05$; ${ }^{* *} p<0.01$.

tested by the two-tailed Student's $t$ test. The criterion for significance was defined as $p<0.05$. When two parameters had a significant $R$, we performed a regression test and plotted a regression line. Values are expressed as mean \pm SEM unless otherwise indicated.

\section{Results}

We used VGAT-ChR2(H134R)-EYFP mice to distinguish GABAergic neurons from glutamatergic neurons in vivo. Using this optogenetics method, we recorded the responses to sound from 135 GABAergic and 166 glutamatergic neurons. These two classes of neurons differed primarily in their spontaneous firing rates and responses to modulated sound, but other properties were heterogeneous and not easily separable.
GABAergic and glutamatergic neurons did not differ in spike shape or width

We compared the spike shapes of GABAergic and glutamatergic neurons in IC identified optogenetically and observed two different spike shapes: trough-peak spikes (where trough preceded the eak) and peak-trough spikes (vice versa, Fig. 1). These pattern the neuron (Henze et al., 2000). We measured the 20\% spike width, the interval between the trough and peak, and the peak/trough amplitude ratio (Fig. $1 B$ ), the same metrics used to identify interneurons in the neocortex (Moore and Wehr, 2013; Lee et al., 2016) but found no significant difference between GABAergic and glutamatergic neurons (Table 1). This suggests that GABAergic and glutamatergic classes have no distinctive difference in spike shape in IC.

\section{GABAergic neurons had higher spontaneous firing rates than glutamatergic neurons}

We compared the spontaneous firing of the GABAergic neurons to that of glutamatergic neurons (Fig. 2A). The spontaneous firing rates of the GABAergic neurons $(0.88 \pm 0.34 \mathrm{~Hz}, n=135)$ were significantly higher than those of the glutamatergic neurons $(0.32 \pm 0.15 \mathrm{~Hz}, n=166$, $p=0.014$, Wilcoxon signed-rank test). However, most neurons in these anesthetized mice had no spontaneous firing (GABAergic neurons, 68.1\%, glutamatergic neurons, $79.5 \%$ ).

\section{GABAergic and glutamatergic neurons had heterogeneous spike thresholds, latencies, and rate-level functions}

The spike thresholds of GABAergic and glutamatergic neurons in the IC were diverse (Fig. $2 B$ ) and showed the expected dependency on the CF (Egorova et al., 2001). When the CF was low $(<8 \mathrm{~Hz})$ or high $(>32 \mathrm{~Hz})$, the thresholds were higher (Fig. 2B). The mean threshold of the GABAergic neurons $(33.1 \pm 1.6 \mathrm{~dB}$, $n=75$ ) was not significantly different from that of the glutamatergic neurons $(37.1 \pm 1.5 \mathrm{~dB}, n=101, p=0.078$, Wilcoxon signed-rank test). The CF of the both classes was correlated with the recording depth (Fig. $2 C$; $r=0.545$ and $r=0.550$ for GABAergic and glutamatergic neurons, respectively), consistent with the general tonotopicity of the IC (Romand and Ehret, 1990; Portfors and Roberts, 2014). The CFs and the spike latencies were weakly correlated ( $r=0.032$ and $r=-0.117$ for GABAergic and glutamatergic neurons, respectively).

For both GABAergic and glutamatergic neurons, the spike latency showed a weak but significant negative correlation with the recording depth (Fig. $2 D ; r=-0.275$ and $r=-0.269$ for GABAergic and glutamatergic neurons, respectively; $p<0.01$ ), and both classes were heterogeneous populations with both short- and long-latency subtypes. Latencies of both types were 
similar when sorted according to recording depth. The mean spike latencies of GABAergic neurons ranged from $34.0 \pm$ $5.3 \mathrm{~ms}$ at $0-0.4 \mathrm{~mm}$ depth $(n=4)$ to $13.8 \pm 3.4 \mathrm{~ms}(n=8)$ at $1.6-2.0 \mathrm{~mm}$ depth. The spike latencies of glutamatergic neurons ranged from $26.9 \pm 6.3 \mathrm{~ms}(n=$ $10)$ at $0-0.4 \mathrm{~mm}$ depth to $15.3 \pm 2.6 \mathrm{~ms}$ $(n=15)$ at the depth of $1.6-2.0 \mathrm{~mm}$ ( $p$ values of Wilcoxon signed-rank test between GABAergic and glutamatergic neurons were $0.257,0.424,0.95,0.093$, and 0.559, respectively).

Both GABAergic and glutamatergic neurons can have either monotonic or nonmonotonic rate level functions (RLFs, Fig. 2E-I). The MI (Fig. 2E, F; see Materials and Methods) indicated similar RLFs for both GABAergic $(0.74 \pm 0.03, n=74)$ and glutamatergic neurons $(0.79 \pm 0.03$, $n=101, p=0.092$, Wilcoxon signed-rank test) (Fig. 2F). Both cell groups had similar proportions of monotonic $(0.8 \leq \mathrm{MI}$, GABA, 55.4\%, GLU, 59.2\%), moderately nonmonotonic $(0.4 \leq \mathrm{MI}<0.8$, GABA, 29.7\%, GLU, 29.1\%) and strongly nonmonotonic RLFs $(\mathrm{MI}<0.4$, GABA, $14.9 \%$, GLU, 9.7\%) ( $p=0.573$, Fisher's exact test).

There was no overall difference in the response gain of GABAergic and glutamatergic classes in the IC. We measured the dynamic range for sound level $(\Delta \mathrm{dB}$, Fig. $2 E, G)$, firing rate $(\Delta \mathrm{FR}$, Fig. $2 E, H)$, and the slope for RLFs (dividing $\Delta \mathrm{FR}$ by $\Delta \mathrm{dB}$, Fig. 2I). For comparison of these parameters, we separated the neurons by their cell types and monotonicity (Fig. 2G-I). Both GABAergic and glutamatergic strongly nonmonotonic neurons have lower values for $\Delta \mathrm{dB}$ and $\Delta \mathrm{FR}$ (Fig. 2G,H) that likely reflects a weak correlation with MI $(\Delta \mathrm{dB}, \mathrm{GABA}, r=0.348$, GLU, $r=$ 0.315; $\Delta \mathrm{FR}, \mathrm{GABA}, r=0.405$, GLU, $r=$ $0.190)$. The strongly nonmonotonic glutamatergic neurons had lower values for both $\Delta \mathrm{dB}(5.0 \pm 1.0 \mathrm{~dB}, n=8)$ and $\Delta \mathrm{FR}$ $(10.1 \pm 2.0 \mathrm{~Hz})$ than several other groups (Fig. $2 G, H ; \Delta \mathrm{dB}, p=0.0008, \Delta \mathrm{FR}, p=$ 0.0016 , Kruskal-Wallis test), but there were no significant differences in the slope among the groups (Fig. $2 I ; p=0.7432$, Kruskal-Wallis test). These results suggested that the strongly nonmonotonic glutamatergic neurons are a distinct subgroup in the IC.

GABAergic and glutamatergic neurons had heterogeneous FRAs and binaural responses

Spectral tuning of GABAergic and glutamatergic neurons was diverse in the IC (Fig. $3 A, C$ ). Figure $3 A$ shows FRA from
A
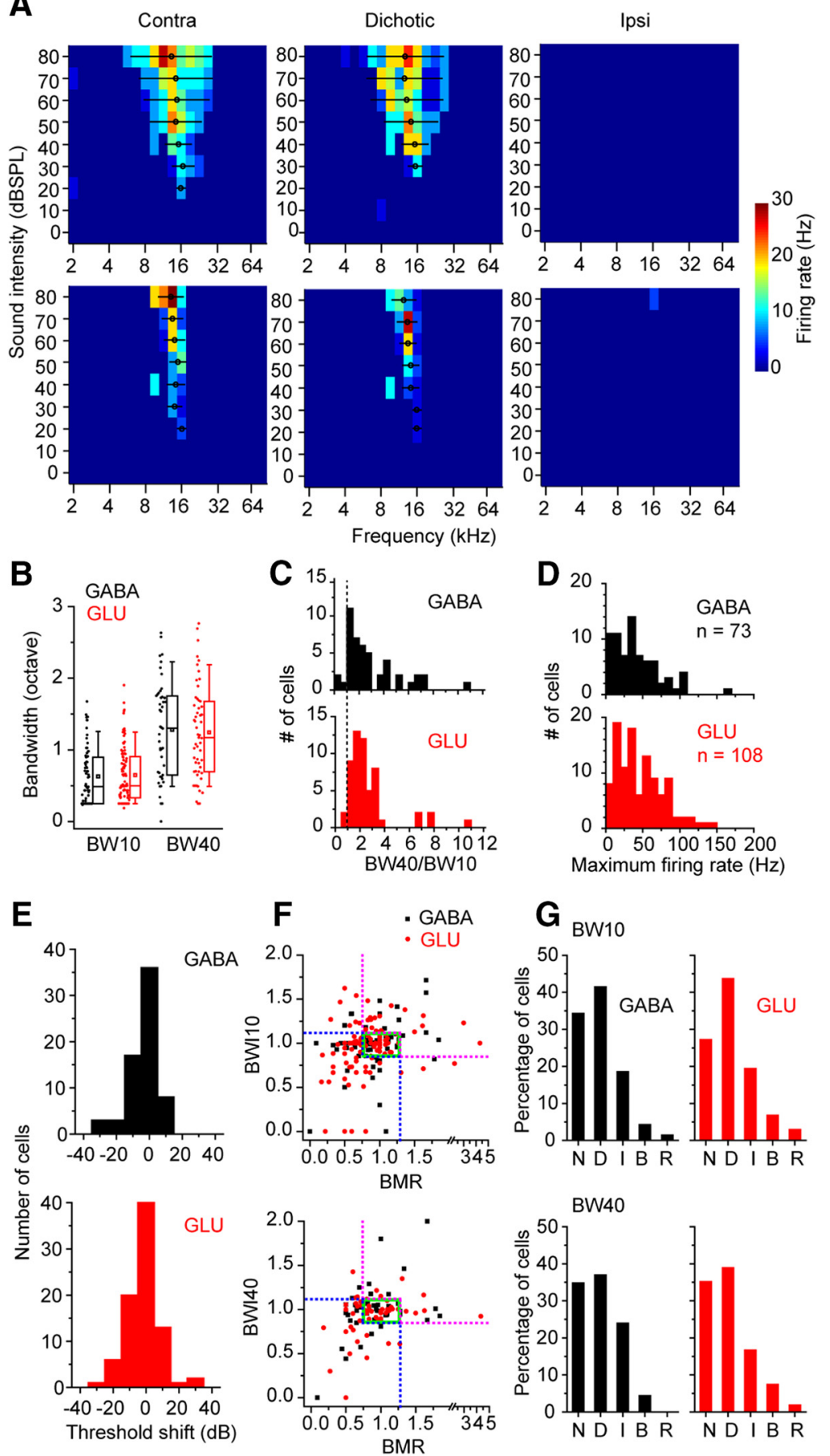

Figure 3. FRAs of GABAergic and glutamatergic neurons in the IC. A, FRAs from two GABAergic neurons. Left panels, FRAs to contralateral tones. Middle panels, FRAs to diotic tones. Right panels, FRAs to ipsilateral tones. These neurons had no response to ipsilateral tones. Circles represent the centroids. Lines in FRAs indicate BWs. $\boldsymbol{B}$, The FRA BWs. The FRA BWs at $10 \mathrm{~dB}$ and $40 \mathrm{~dB}$ above threshold (BW10 and BW40) were measured and compared between GABAergic and glutamatergic neurons. $C$, Histograms of the ratio of BW40 to BW10. Dotted line indicates the ratio of 1. D, Histograms of the maximum firing rates of GABAergic and glutamatergic neurons in their FRAs. $\boldsymbol{E}$, The threshold shift between the FRAs to contralateral and diotic tones. The positive value indicates that the threshold to diotic tones was higher than the threshold to contralateral tones. $\boldsymbol{F}$, The comparison of the BW and maximum firing rate in the contralateral and diotic FRAs. The BWI (see Materials and Methods) was plotted against the rate ratio (BMR). We calculated BWI for BW10 (top) and BW40 (bottom). Green squares represent the range within $25 \%$ changes in $B W$ and rate. Blue and magenta dotted lines indicate the border of the categories of binaural effect. $G$, The percentage of the neurons in different categories of binaural effect on FRA. The binaural effect was classified into five categories: No change (N), Decreased (D), Increased (I), BW increasedrate decreased (B), and Rate increased-BW decreased (R). 
A

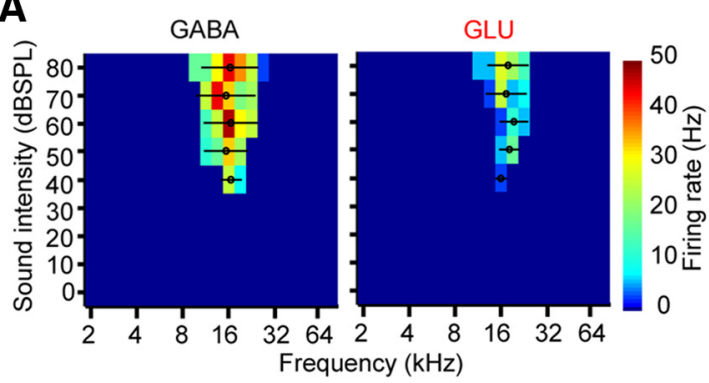

B
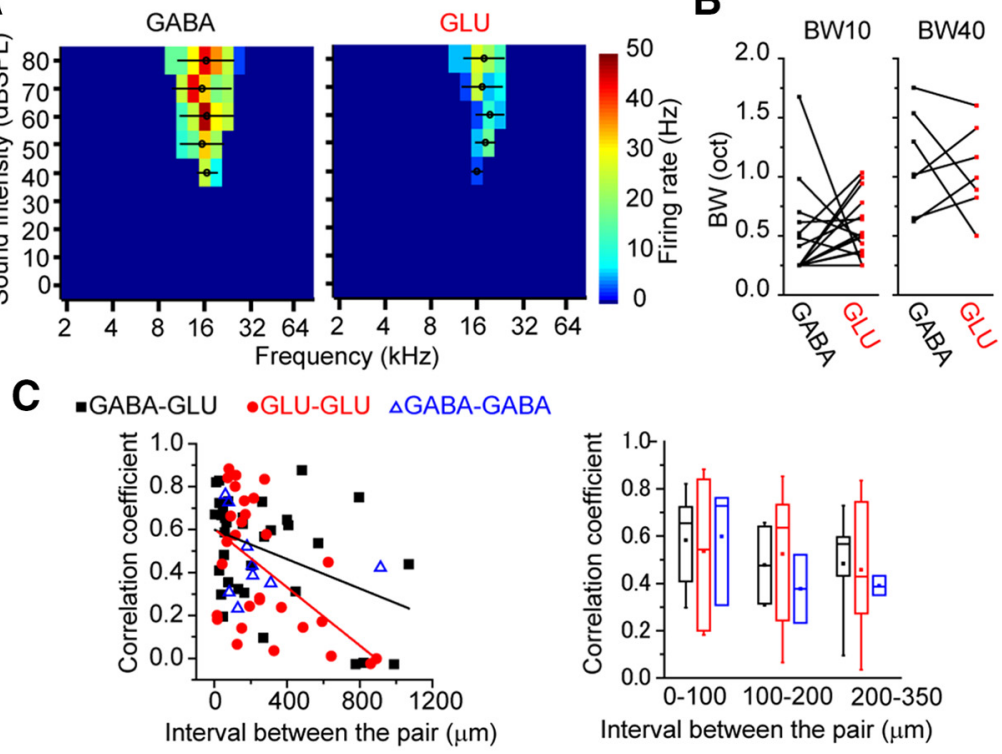

D
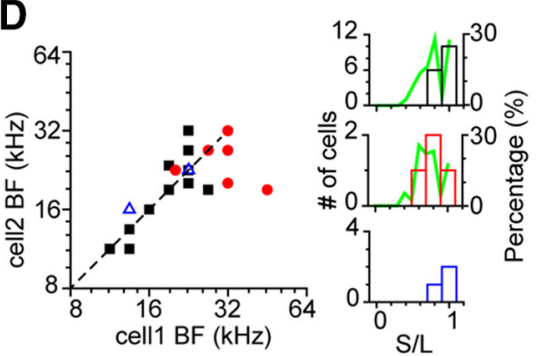

$\mathbf{E}$
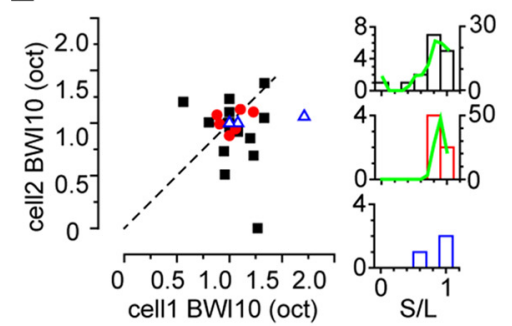

$\mathbf{F}$

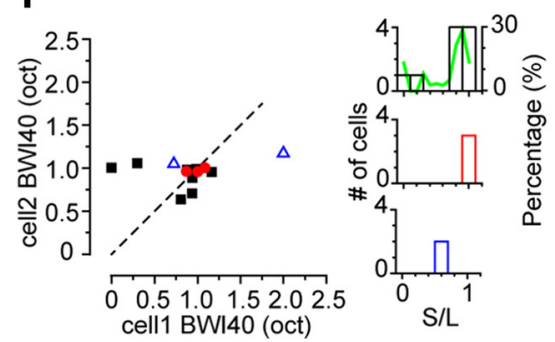

G

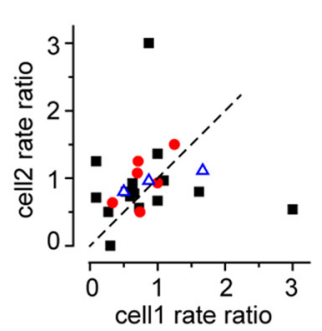

Figure 4. Closely located IC neurons shared similar FRAs. A, The FRAs of closely located GABAergic (left) and glutamatergic (right) neurons. The distance between these neurons was $76 \mu \mathrm{m}$. B. The comparison of the BWs between nearby GABAergic and glutamatergic neuron within 0-100 $\mu \mathrm{m}$. Left panel, BW10. Right panel, BW40. C, Left, The correlation coefficient of the FRAs of paired neurons was plotted against the distance between the neurons. Right, The data were separated by the ranges of the distance between the pair (0-100, 100-200, and 200-350 $\mu \mathrm{m}$ ) and compared. Correlation coefficients: GABA-GLU, $r=0.58 \pm 0.05, n=15$; GLU-GLU, $r=0.54 \pm 0.10, n=7 ;$ GABA-GABA, $r=0.60 \pm 0.15, n=3 ; 100-200 \mu \mathrm{m}$ :GABA-GLU, $r=0.48 \pm 0.09, n=4 ;$ GLU-GLU, $r=0.52 \pm 0.10, n=9 ;$ GABA-GABA, $r=0.38 \pm 0.14, n=2 ; 200-350 \mu \mathrm{m}$ : GABA-GLU, $r=0.48 \pm 0.11, n=5 ;$ GLU-GLU, $0.46 \pm$ $0.13, n=6 ; G A B A-G A B A, 0.39 \pm 0.02, n=3 . D-G$, Closely located neuron pairs $(0-100 \mu \mathrm{m})$ are compared for $(\boldsymbol{D})$ BF, (E) BWI10, $(\boldsymbol{F})$ BWI40, and $(\boldsymbol{G})$ binaural rate ratio. Left plots, Scattered plots of the parameter of paired neurons. Right panels, Histograms of the ratio of the parameters of the paired neurons. The ratio of the smaller value to the larger value is shown.

two GABAergic neurons that differ in the sharpness of their frequency tuning. There was no significant difference between BW of the GABAergic and glutamatergic neurons at 10 and $40 \mathrm{~dB}$ above threshold (Fig. 3B; BW10, $0.32 \pm 0.04$ octave and $0.29 \pm$ 0.02 octave for GABAergic and glutamatergic neurons, respectively, $p=0.949$, Wilcoxon signed-rank test; BW40, $0.66 \pm 0.05$ octave and $0.61 \pm 0.04$ octave, $p=0.48)$. The ratio of BW40 to BW10 (Fig. 3C) showed that most neurons of both classes had a V-shaped FRA with ratio values $>1$. Only $6 \%$ of GABAergic ( 3 of $46)$ and $4 \%$ of glutamatergic neurons ( 2 of 55$)$ had ratios $<1.0$ indicating an I-type or O-type FRA (Ramachandran et al., 1999).
There was no significant difference in the mean value of this ratio between GABAergic $(2.20 \pm 0.32)$ and glutamatergic classes $(2.61 \pm 0.26, p=0.829$, Wilcoxon signed-rank test). The maximum firing rate in response to contralateral tones did not differ for both classes of neurons (Fig. $3 D ; 40.6 \pm 3.7 \mathrm{~Hz}$ and $46.0 \pm 3.0 \mathrm{~Hz}$ for GABAergic and glutamatergic neurons, respectively; $p=0.188$, Wilcoxon signedrank test).

To ask whether cell class predicted the binaural response, we recorded the FRA to contralateral, ipsilateral, and diotic tones in the same stimulus waveform (Fig. $3 A$ ). Most GABAergic (49 of 73) and glutamatergic neurons (78 of 108) did not fire in response to stimuli in the ipsilateral ear alone (Fig. $3 A$ ); and in 54\% of GABAergic neurons (36 of 67 ) and 58\% of glutamatergic neurons (57 of 99), there was no threshold shift due to diotic tone presentation (Fig. 3E). When the threshold evoked by the contralateral tones was compared with that evoked by the diotic tones, we found that slightly more neurons had negative thresholds shifts than positive threshold shifts (mean threshold shift, $-3.6 \pm 1.1 \mathrm{~dB}$ for GABAergic and $-1.4 \pm 0.9 \mathrm{~dB}$ for glutamatergic neurons, $p=0.240$, Wilcoxon signed-rank test).

To evaluate suprathreshold binaural effects, we compared the maximum firing rate and $\mathrm{BW}$ in contralateral and diotic FRAs. For this comparison, we calculated the BMR and the BWI (see Materials and Methods). Both BWI and BMR clustered $\sim 1.0$ indicating little binaural effect (Fig. $3 F)$. The BWI and BMR were moderately correlated in GABAergic neurons (correlation coefficient, 0.45 and 0.44 for BWI10 and BWI40, respectively), whereas they were less well correlated in glutamatergic neurons (correlation coefficient, 0.20 and 0.11 , for BWI10 and BWI40, respectively). Changes $<25 \%$ were classified as no change $(\mathrm{N})$. Otherwise, both parameters decreased (Fig. 3F, blue dotted lines), increased (Fig. 3F, magenta dotted lines), or were changing in different directions (BW increased-rate decreased, Fig. $3 F$, top left area; Rate increased-BW decreased, Fig. 3F, bottom right area). The majority of neurons showed decreased or no change (Fig. $3 G$ ) in both GABAergic (decreased, BW10, 41.4\%, BW40, 37.0\%; no change, BW10, 34.3\%, BW40, 34.9\%) and glutamatergic neurons (decreased, BW10, 43.7\%, BW40, 38.9\%; no change, BW10, 27.2\%, BW40, 35.2\%). Thus, the effect of ipsilateral tones was more frequently suppressive than facilitative in the FRA. The percentage of each class was not significantly different between GABAergic and glutamatergic neurons (Fig. $3 G$; $\mathrm{BW} 10, p=0.577$, BW40, $p=0.069$, Fisher's exact test). Consequently, these results suggest that GABAergic and glutamatergic classes did not predict the binaural responses. 
Nearby GABAergic and glutamatergic neurons were more similar in their FRA Pairs of nearby neurons can share similar frequency tuning to monaural sounds due to shared inputs (Fig. 4A). We compared the recordings of pairs of GABAergic and glutamatergic neurons in the same mouse to test whether they might share the same inputs and (Fig. 4A). The BW of GABAergic and glutamatergic neurons within 0-100 $\mu \mathrm{m}$ was similar (Fig. $4 B$; BW10, $p=0.182$, BW40, $p=0.938$, paired Wilcoxon signed-rank test). When the correlation coefficient of FRAs was plotted against the distance between pairs of GABA-GLU and GLU-GLU neurons, the correlation coefficient had a statistically significant $(p<0.05)$ negative correlation with the interval (Fig. 4C, left; GABAGLU, $r=-0.414$, GLU-GLU, $r=$ -0.542). The FRAs were moderately correlated between neuron pairs within 0-350 $\mu \mathrm{m}$, regardless of their combination of neuronal types (Fig. $4 C$, right).

The ratio of BF, BWI10, BWI40, and BMR values in pairs of IC neurons within $0-100 \mu \mathrm{m}$ was used to measure the similarity of the pair (smaller/larger; Fig. $4 D-$ $G)$. The GABAergic and glutamatergic pairs shared similar BF values (Fig. 4D; $r=0.92 \pm 0.03, n=16)$, but in other parameters, they were less similar (Fig. $4 E-G$; BWI10, $r=0.75 \pm 0.06, n=16$, BWI40, $r=0.69 \pm 0.12, n=8$, BMR, $r=$ $0.54 \pm 0.08, n=16)$. To evaluate whether the ratios differed from chance levels, we compared the measured ratios with bootstrapped values $(\times 1000$; Fig. 4D-G, green lines). Bootstrapping was done by extracting a random pair of values from the paired recorded data within $0-100 \mu \mathrm{m}$. The measured BFs were significant above the chance level ( $p=0.0018$, Wilcoxon signed-rank test), whereas the ratios of other parameters were not significantly different from chance ( $p=0.931, p=0.996$, and $p=0.906$ for BWI10, BWI40, and $\mathrm{BMR}$, respectively, Wilcoxon signed-rank test). For glutamatergic neuron pairs, the ratios of the $\mathrm{BF}(0.80 \pm 0.09, n=6, p=0.549)$, BWI10 $(0.90 \pm 0.02, n=6, p=0.843)$, and BMR $(0.70 \pm 0.06$, $n=6, p=0.589$ ) were not different from the chance level (Wilcoxon signed-rank test). Other pairings were excluded because of small sample size. Thus, pairs of nearby IC neurons often shared a similar BF, but the other properties were less similar than that expected by chance pairings.

\section{PSTHs had diverse temporal patterns in the IC}

When we compared the properties of PSTHs in response to CF tones $(100 \mathrm{~ms})$, we found that the PSTH peak time and duration (20\% width; see Materials and Methods) for different sound intensities were distributed within similar ranges for both GABAergic and glutamatergic neurons (Fig. 5A; Table 2). The PSTHs of nearby neurons were diverse and poorly correlated (Fig. 5B; some points are $<0)$.

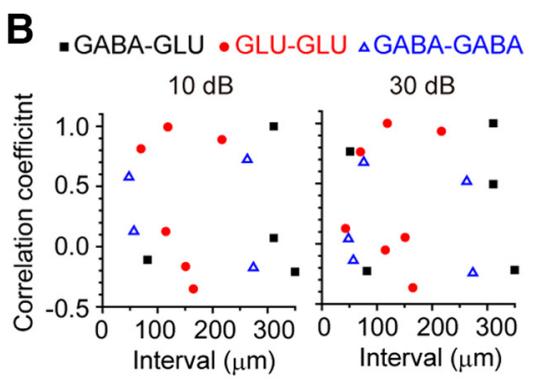

E

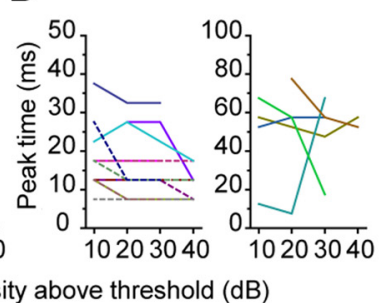

G

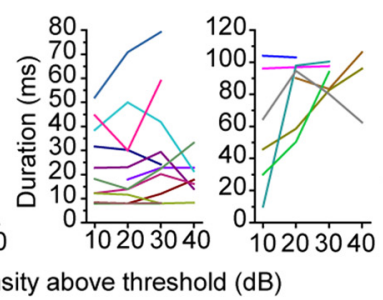

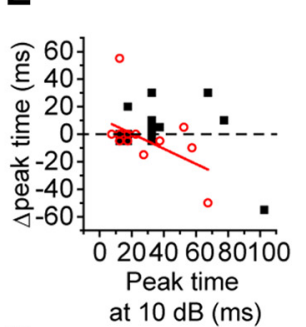

H

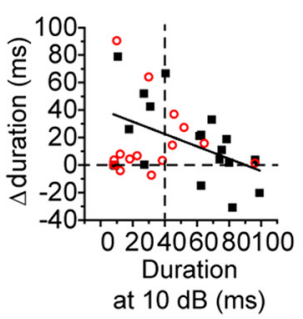

Figure 5. PSTH patterns of GABAergic and glutamatergic neurons in the IC. $A$, The duration of the PSTH was plotted against the eak time of the PSTH. Panels represent responses to different sound intensities ( 10 and $30 \mathrm{~dB}$ above threshold). $\boldsymbol{B}$, The correlation

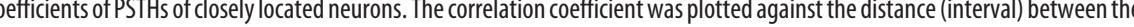
ir. Each panel represents the response to a different sound intensity ( 10 and $30 \mathrm{~dB}$ above threshold). C, D, The peak time plotted (10 - $40 \mathrm{~dB}$ above threshold). C, GABAergic neurons. D, Glutamatergic neurons. Left panels, Data whose data from a neuron in these and the subsequent plots. $\boldsymbol{E}, \Delta$ peak time was plotted against the peak time at $10 \mathrm{~dB}$ above threshold. Red line indicates the fitted line for the data of glutamatergic neurons $(y=11.42-0.55 x)$. Dotted line indicates the $0 \mathrm{~ms}$ of $\Delta$ peak time. $\boldsymbol{F}, \mathbf{G}$, Duration plotted against sound intensities (10 - $40 \mathrm{~dB}$ above threshold). $\boldsymbol{F}$, GABAergic neurons. Left panels, Data maximum value was $<85$ ms. Right panels, Data whose maximum value was $>85 \mathrm{~ms}$. $\mathbf{G}$, Glutamatergic neurons. Left a $(y=40.46-0.45 x)$. Horizontal lines indicate the $0 \mathrm{~ms}$ of $\Delta$ duration at $10 \mathrm{~dB}$ above threshold. Vertical lines indicate the $40 \mathrm{~ms}$ of the duration at $10 \mathrm{~dB}$ above threshold.

\section{Table 2. PSTH parameters}

\begin{tabular}{llll}
\hline & GABAergic & Glutamatergic & $p$ \\
\hline Peak time (ms) dB above threshold & & & \\
$10 \mathrm{~dB}$ & $33.2 \pm 5.6(19)$ & $22.6 \pm 4.4(18)$ & 0.118 \\
$20 \mathrm{~dB}$ & $26.3 \pm 3.5(20)$ & $24.5 \pm 4.6(20)$ & 0.291 \\
$40 \mathrm{~dB}$ & $33.2 \pm 7.4(14)$ & $20.5 \pm 5.9(10)$ & 0.299 \\
$20 \%$ width (ms) dB above threshold & & & \\
$10 \mathrm{~dB}$ & $53.3 \pm 7.0(19)$ & $33.7 \pm 7.1(18)$ & 0.092 \\
$20 \mathrm{~dB}$ & $61.5 \pm 6.5(20)$ & $44.5 \pm 8.0(20)$ & 0.098 \\
$40 \mathrm{~dB}$ & $65.2 \pm 10.2(14)$ & $39.8 \pm 11.3(10)$ & 0.278 \\
\hline
\end{tabular}

For most GABAergic and glutamatergic neurons, the peak time did not change dramatically with sound level (Fig. 5C,D), but the duration of the response was sensitive to sound intensity (Fig. $5 F, G$ ). In both GABAergic and glutamatergic neurons (Fig. $5 E$ ), the mean of the $\Delta$ peak time ( $30 \mathrm{~dB}$ response less $10 \mathrm{~dB}$ response) was $\sim 0$ (GABA, $1.6 \pm 4.0 \mathrm{~ms}, \mathrm{GLU},-2.2 \pm 5.0 \mathrm{~dB}, p=$ 0.175 , Wilcoxon signed-rank test). More GABAergic neurons 
A

GABA

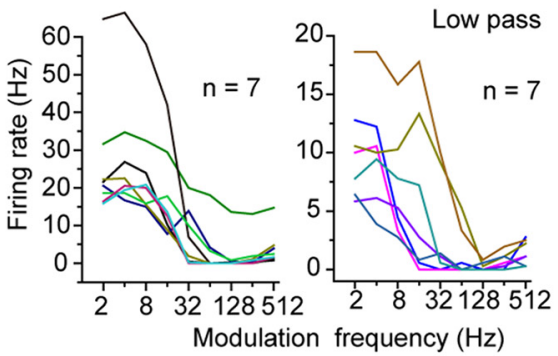

B

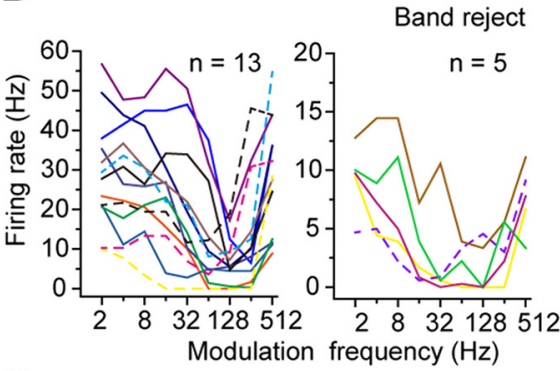

C

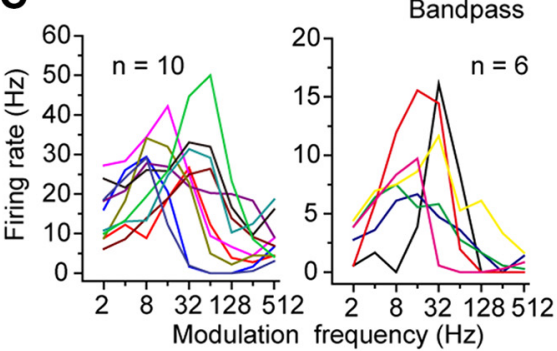

D

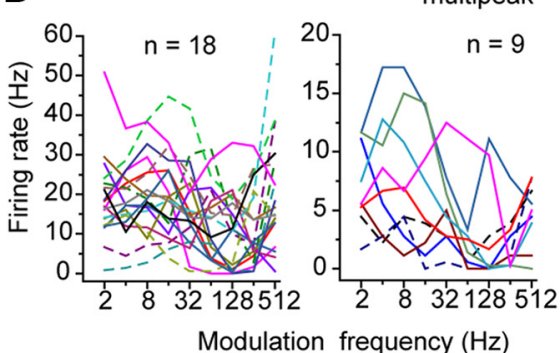

GLU
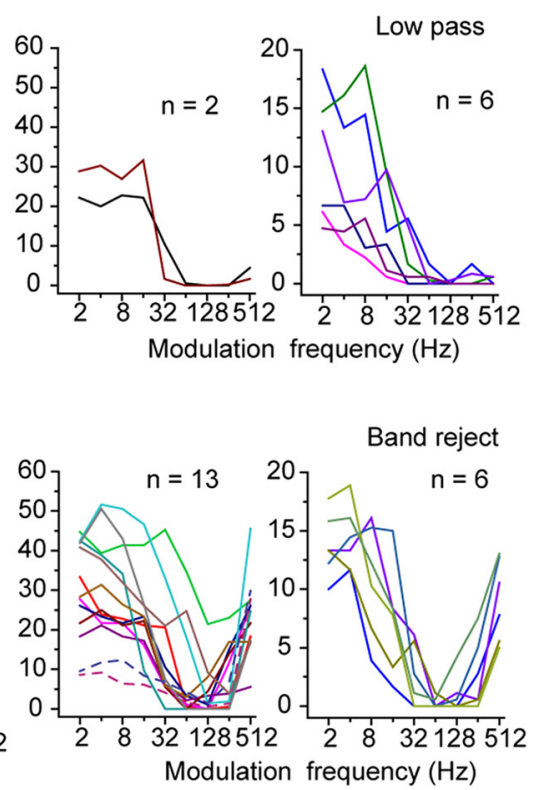

Bandpass
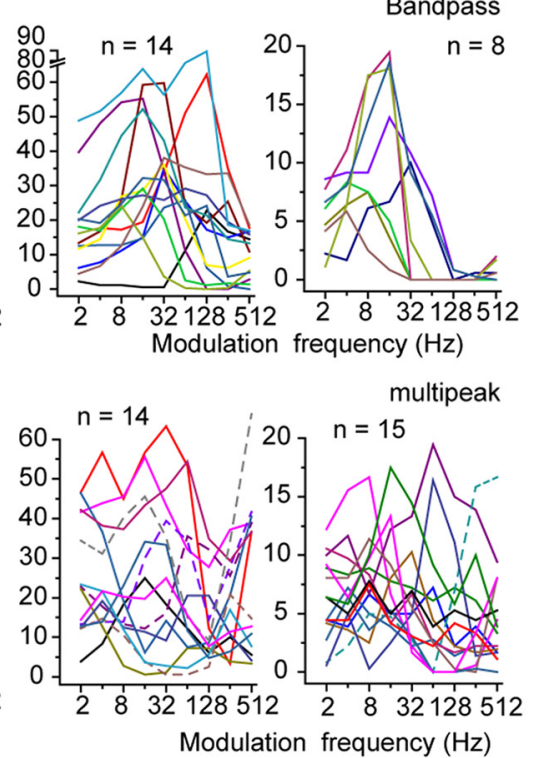

G GABA

GLU

H GABA

GLU

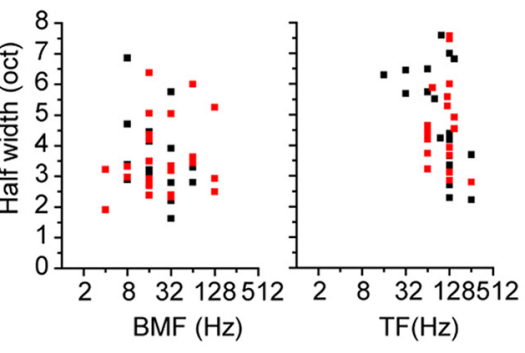

Figure 6. rMTF of GABAergic and glutamatergic neurons in response to AM sounds. $\boldsymbol{A}-\boldsymbol{I}$, Different types of the rMTFs: $\boldsymbol{A}$, low pass; $\boldsymbol{B}$, band reject; $\boldsymbol{C}$, bandpass; $\boldsymbol{D}$, multipeak; $\boldsymbol{E}$, high pass. Left panels, Recordings from GABAergic and neurons. Right panels, Recordings from glutamatergic neurons. For each cell type, the data are divided into two panels to facilitate visualization of the traces. Left panels, Data whose maximum firing rate was $>20 \mathrm{~Hz}$. Right panels, Data whose maximum firing rate was $<20 \mathrm{~Hz}$. High pass neurons were rare in GABAergic neurons. $\boldsymbol{F}$, The cutoff frequencies of low pass neurons of GABAergic and glutamatergic neurons. $\mathbf{G}$, The best modulation frequency and the half-width of the rMTF were measured in the bandpass neurons. $\boldsymbol{H}$, The trough frequency and half-width of the rMTF were measured in the band-rejected neurons.
(36.8\%, 7 of 19) had positive $\Delta$ peak time than glutamatergic neurons $(12.5 \%, 2$ of 16); however, the difference was not significant ( $p=0.135$, Fisher's exact test). In the glutamatergic neurons, $\Delta$ peak time was negatively correlated with the peak time at $10 \mathrm{~dB}$ above threshold $(r=$ $-0.525, p=0.037)$, although it was not in GABAergic neurons $(p=0.215)$. This result suggested that the acceleration of the peak time might be stronger in the glutamatergic neurons than in GABAergic neurons, especially the neurons with buildup responses at low sound intensity.

In contrast to $\Delta$ peak time, $\Delta$ duration (30 $\mathrm{dB}$ response less $10 \mathrm{~dB}$ response) was positive in most neurons, regardless of the cell types (Fig. 5H; GABA, $16.5 \pm 6.6 \mathrm{~ms}$; GLU, $16.5 \pm 6.7, p=0.857$, Wilcoxon signed-rank test). In the GABAergic neurons, $\Delta$ duration was negatively correlated with duration at $10 \mathrm{~dB}(r=-0.477, p=$ $0.039)$ but not in the glutamatergic neurons $(p=0.884)$. This might reflect that more glutamatergic neurons with short durations at $10 \mathrm{~dB}$ had small values of $\Delta$ duration reflecting a similar duration of response regardless of sound level (Fig. $5 H)$. To examine this, we separated the $\Delta$ duration values into two groups based on the duration at $10 \mathrm{~dB},<$ or $>40 \mathrm{~ms}$ (Fig. $5 \mathrm{H}$, vertical dotted line). The glutamatergic neurons with low values of duration at $10 \mathrm{~dB}$ had shorter $\Delta$ duration than GABAergic neurons (GABA, $28.4 \pm 11.7$ ms, $n=7$; GLU, $15.3 \pm 9.5 \mathrm{~ms}, n=11$ ), but there was no significant difference ( $p=0.869$, Steel-Dwass test). These results show that PSTH duration becomes more sustained as sound intensity increases in both GABAergic and glutamatergic neurons, although there is a tendency for more glutamatergic neurons to have transient responses that are invariant for sound level.

\section{GABAergic and glutamatergic neuron differences in rMTFs}

The proportion of the rMTF types in response to sinusoidal AM noise differed somewhat for GABAergic and glutamatergic (Fig. $6 ; p=0.273$, Fisher's exact test). Only glutamatergic neurons showed high pass responses (Fig. $6 E$ ). In contrast, more GABAergic neurons (15.4\%) had a low pass rMTF than glutamatergic neurons $(7.8 \%$, Fig. $6 A)$. For the other types of rMTF, GABAergic and glutamatergic showed similar proportions (Fig. $6 B-D$; Table 3 ). In response to raised sine envelopes, more neurons showed low pass and bandpass responses, whereas fewer neu- 
rons showed band reject and multipeak responses (Table 3). This trend was observed in both GABAergic and glutamatergic neurons. Nevertheless, glutamatergic neurons continued to have more high pass responses than GABAergic neurons for sounds modulated by raised sine (Table 3 ).

The rMTFs of GABAergic and glutamatergic neurons covered similar ranges and had no significant differences in the cutoff frequency of low pass rMTFs (Fig. $6 F$ ), the half-widths (HWs) of bandpass and band reject rMTFs (Fig. 6G,H). They also did not differ in the best modulation frequency (BMF) for bandpass rMTFs and trough frequency (TF) for band reject rMTFs for both SAM and raised sine stimuli (Fig. $6 G, H$; Table 4; SAM, $p=0.212$, $p=0.460, p=0.967, p=0.738$, and $p=0.607$, for cutoff frequency, BMF, HW of bandpass, TF, and HW of band reject, respectively, Wilcoxon signed-rank test; raised sine, $p=0.986$, $p=0.210, p=0.566, p=0.158$, and $p=0.270$, respectively). When the bandpass and band reject rMTFs were compared, the BMFs were significantly lower than the TFs (Fig. 6G,H; Table 4, $p<0.05$, Wilcoxon signed-rank test) for both GABAergic and glutamatergic neurons.
Table 3. The response types of rMTFs

\begin{tabular}{lclllll}
\hline & Low pass & Band reject & Band pass & Multipeak & High pass & Low rate \\
\hline SAM & & & & & & \\
$\quad$ GABA & $14(15.4)$ & $18(19.8)$ & $16(17.6)$ & $27(29.7)$ & $0(0)$ & $16(17.6)$ \\
$\quad$ GLU & $8(7.8)$ & $19(18.4)$ & $22(21.3)$ & $29(28.2)$ & $4(3.9)$ & $21(20.4)$ \\
Raised sine & & & & & & \\
GABA & $19(22.4)$ & $9(10.6)$ & $20(23.5)$ & $19(22.4)$ & $1(1.2)$ & $17(20.0)$ \\
GLU & $15(16.5)$ & $9(9.9)$ & $29(31.9)$ & $19(20.9)$ & $3(3.3)$ & $16(17.6)$ \\
\hline
\end{tabular}

Table 4. The parameters of low pass, band pass, and band reject rMTFs

\begin{tabular}{|c|c|c|c|c|c|}
\hline & $\begin{array}{l}\text { Cutoff } \\
\text { frequency }(\mathrm{Hz})\end{array}$ & $\mathrm{BMF}(\mathrm{Hz})$ & HW (0ct) & $\mathrm{TF}(\mathrm{Hz})$ & $\mathrm{HW}(\mathrm{Hz})$ \\
\hline \multicolumn{6}{|l|}{ SAM } \\
\hline GABA & $21.2 \pm 3.6(14)$ & $24.5 \pm 4.6(16)^{*}$ & $3.7 \pm 0.3$ & $110.8 \pm 14.8(19)^{*}$ & $4.9 \pm 0.4$ \\
\hline GLU & $14.1 \pm 2.9(8)$ & $37.7 \pm 8.0(24)^{*}$ & $3.6 \pm 0.3$ & $113.9 \pm 10.4(20)^{*}$ & $4.6 \pm 0.3$ \\
\hline \multicolumn{6}{|l|}{ Raised sine } \\
\hline GABA & $12.7 \pm 3.1(19)$ & $29.6 \pm 5.0(20)^{*}$ & $3.0 \pm 0.3$ & $110.8 \pm 14.8(11)^{*}$ & $6.3 \pm 0.4$ \\
\hline GLU & $12.6 \pm 2.4(14)$ & $48.4 \pm 8.0(29)^{*}$ & $3.1 \pm 0.2$ & $97.5 \pm 12.7(9)^{*}$ & $5.6 \pm 0.4$ \\
\hline
\end{tabular}

*BMFs were significantly lower than TFs $(p<0.05)$.
GABAergic and glutamatergic neurons differed in temporal synchronization to AM sound

We compared GABAergic and glutamatergic neurons in their degree of synchronization to AM noise and raised sine noise and found differences in the response to raised sine (Fig. 7). In the response to AM noise (Fig. 7A, left), GABAergic and glutamatergic neurons had similar percentages of synchronized neurons to different modulation frequencies $(p=0.910$, paired Wilcoxon signed-rank test). However, in the response to raised sine AM sound (Fig. 7A, right), GABAergic and glutamatergic neurons had different percentages of synchronized neurons ( $p=$ 0.0078 , paired Wilcoxon signed-rank test): more glutamatergic neurons than GABAergic neurons showed synchronization to $\mathrm{AM}$ when the modulation frequency increased (Fig. $7 A$; see the percentages $>8 \mathrm{~Hz}$ ). Because the raised sine AM sound has sharper envelopes than the SAM tone (Bernstein and Trahiotis, 2010), this result suggests that glutamatergic neurons might follow rapid temporal changes in the envelope better than GABAergic neurons.

We also found differences in the strength of phase-locking to the envelope (tMTFs; Fig. 7B). In response to AM noise, the glutamatergic neurons had a higher vector strength at most modulation frequencies than the GABAergic neurons (significance only at $2 \mathrm{~Hz}, p=0.034$, Wilcoxon signed-rank test; Fig. $7 B$, left). The averaged tMTFs for SAM tones had bandpass shapes for both GABAergic and glutamatergic neurons with peaks $\sim 32-64 \mathrm{~Hz}$ in MTFs (Fig. 7B, left). On the other hand, in the response to raised sine noise, the averaged tMTFs were low pass, and both GABAergic and glutamatergic neurons had high values of vector strength up to 32-64 Hz (Fig. 7B, right). At $64 \mathrm{~Hz}$, glutamatergic neurons had significantly higher vector strength than GABAergic neurons ( $p=0.025$, Wilcoxon signed-rank test) but not at other
SAM

Raised
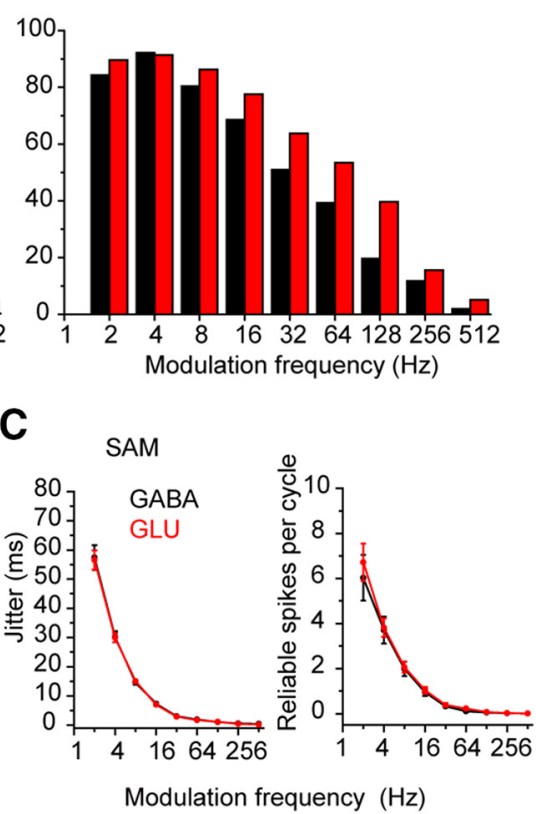

Figure 7. TMTFs of GABAergic and glutamatergic neurons in response to AM sounds. $A$, The percentage of synchronized neurons frequency. Left, SAM. Right, raised sine. ${ }^{*} p<0.05$, the modulation frequencies where the vector strength was significantly different between GABAergic and glutamatergic neurons. C, Spike jitter (left) and reliable spikes per cycle (right) were plotted against modulation frequency. The values in the response to SAM are shown.

modulation frequencies (Fig. $7 B$, right). Spike jitter (Fig. $7 C$, left) and reliable spike number per cycle (Fig. $7 C$, right) in the response to AM sound both showed a decrease as the modulation frequency increased with no difference between the GABAergic and glutamatergic neurons (Fig. 7C). These results suggested that there may be a larger population of glutamatergic neurons synchronized to AM; however, when GABAergic and glutamatergic neurons are synchronized, they are similar in their ability to follow the envelopes.

The response properties of neurons in different IC regions Finally, we examined subregions in the IC for differences of response of GABA and glutamatergic neurons and found that 
A

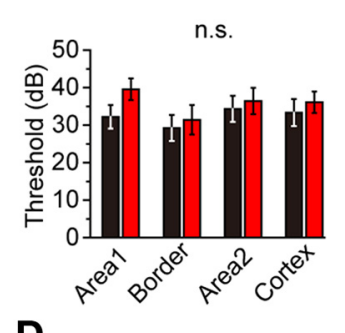

D

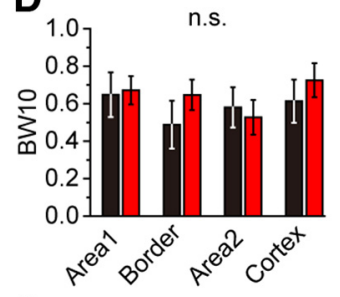

G

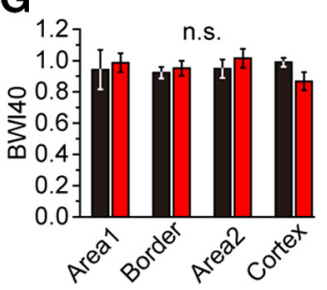

B

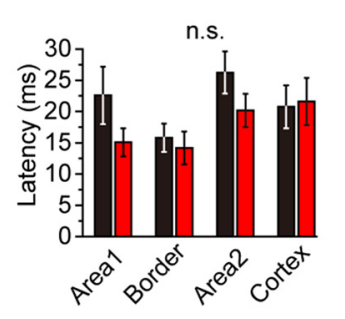

$E$

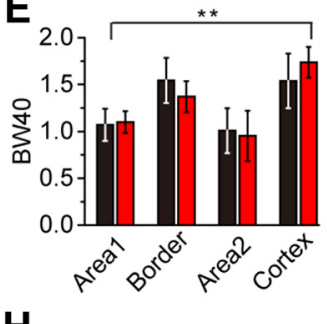

$\mathrm{H}$

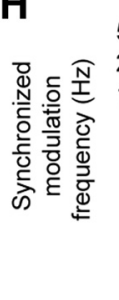

C

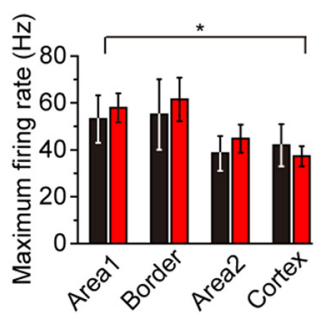

$\mathbf{F}_{1}$
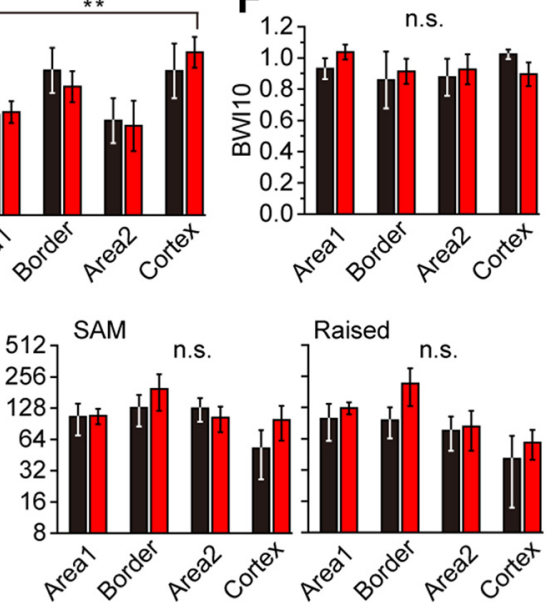

Figure 8. Comparison of the response characters in different subregions in the IC. Individual metrics of the response to sound compared among the subregions in the IC. $\boldsymbol{A}$, Threshold, GABA (black); $n=18, n=13, n=15$, and $n=12$ for Area 1, border, Area 2, and cortex, respectively. The order of the numbers for the different regions is the same in the subsequent descriptions. GLU (red); $n=32, n=14, n=14$, and $n=23$. B, Latency, GABA; $n=17, n=16, n=22$, and $n=12$. GLU; $n=31, n=17, n=$ 24, and $n=22$. C, Maximum rate, GABA; $n=15, n=6, n=14$, and $n=10$. GLU; $n=31, n=14, n=15$, and $n=20 . D$, BW10, $\mathrm{GABA} ; n=15, n=6, n=14$, and $n=10 . \mathrm{GLU} ; n=31, n=14, n=15$, and $n=20 . \boldsymbol{E}, \mathrm{BW} 40, \mathrm{GABA} ; n=12, n=6, n=9$, and $n=6 . \mathrm{GLU} ; n=14, n=9, n=8$, and $n=15 . F, \mathrm{BWI} 10, \mathrm{GABA} ; n=15, n=6, n=13$, and $n=10 . \mathrm{GLU} ; n=31, n=14, n=$ 15, and $n=20$. G, BWI40, GABA; $n=12, n=6, n=9$, and $n=6$. GLU; $n=14, n=9, n=8$, and $n=15$. $\boldsymbol{H}$, The highest modulation frequency with synchronization to SAM (left, GABA; $n=13, n=6, n=11$, and $n=9$. GLU; $n=19, n=8, n=8$, and $n=14$ ) and raised sine (right, GABA; $n=13, n=7, n=11$, and $n=9$. GLU; $n=18, n=8, n=7$, and $n=14$ ). The numbers in the figures indicate the number of data in each bar. $\boldsymbol{C}, \boldsymbol{E}$, The parameters were significantly different among the regions, but not between cell types: ${ }^{*} p<0.05 ;{ }^{* *} p<0.01$.

the responses differed according to region more than to cell class. We applied a two-way factorial ANOVA to CF (data not shown), threshold (Fig. 8A), maximum firing rate (Fig. 8C), BW10 (Fig. $8 D$ ), and BW40 (Fig. $8 E$ ) that satisfied the homogeneity of variance (Bartlett test, $p>0.05$ ), and we examined the statistical difference due to the cell types (GABA vs glutamatergic) and the regions. Areas in the central nucleus were defined based on the relative density of GLYT2- and GAD67-immunostained axons (see Materials and Methods). There was a significant difference in $\mathrm{CF}$, maximum firing rate, and BW40 due to the regions $(p=$ $0.0057, p=0.0271$, and $p=0.0022$, for $\mathrm{CF}$, maximum firing rate, and BW40, respectively), but not due to the cell classes ( $p=$ $0.0692, p=0.4302$, and $p=0.4294$, for CF, maximum firing rate, and BW40, respectively). In consistent with the tonotopic structure, the neurons in Area 1 tended to have higher CFs than those in Area 2 and cortex. The neurons in Area 1 and border had higher firing rate than those in Area 2 and cortex (Fig. $8 \mathrm{C}$ ). On the other hand, the neurons in Area 1 and Area 2 had smaller BW40 than border and cortex neurons (Fig. $8 E$ ), which suggested that the neurons in Area 1 and Area 2 might be more narrowly tuned than other regions. Maximum firing rate and BW40 were only weakly or hardly correlated with CF (maximum firing rate, $r=0.190$ and $r=0.337$ for GABAergic and glutamatergic neurons; BW40, $r=0.036$ and $r=-0.181$ for GABAergic and glutamatergic

neurons). This suggested that the difference of maximum rate and BW40 among the regions were independent from frequency preference. In contrast to the parameters above, there was no significant difference in threshold and BW10 (Fig. $8 A, D)$, due to cell types or regions ( $p>$ 0.05). The other parameters (latency, BWI10, BWI40, and the highest modulation frequency with synchronization) showed no statistical difference between groups (nonparametric Steel-Dwass test, $p>0.05)$. These results suggest that some response characteristics are more likely to be influenced by their location than by the cell type.

\section{Discussion}

The present results showed that IC neurons divided into GABAergic and glutamatergic classes had diverse response properties in most cases. The two cell classes did not show distinct differences in their spike shape or responses to pure tones. However, the GABAergic neurons had a higher rate of spontaneous firing. More differences in the cell types were evident in their response to AM sound. Only glutamatergic neurons had high-pass responses, and glutamatergic neurons had more synchronized responses with higher vector strength. These results suggest that GABAergic and glutamatergic neurons may share similar receptive field but have different temporal properties in the local circuit. Neurons within the same subregion of the IC had similar responses, so the location in the IC may predict response properties better than the glutamatergic or GABAergic class.

\section{Spike shape does not distinguish GABAergic IC neurons}

In the neocortex and hippocampus, the shape of the action potential is often used to separate the glutamatergic pyramidal neurons and parvalbumin-positive GABAergic interneurons (Csicsvari et al., 1999; Niell and Stryker, 2008; Ma et al., 2010; but see Runyan et al., 2010; Moore and Wehr, 2013). Sharp spikes are the hallmarks of fast spiking interneurons and are used to identify a subset of GABAergic neurons in these regions. GABAergic neurons also have been reported to have shorter spikes than other types of neurons in the amygdala (Sosulina et al., 2010), substantia nigra (Ding et al., 2011), and medial septum (Gonzalez-Sulser et al., 2014). However, in the IC, GABAergic and glutamatergic classes were not separable by their spike shape or size. This result is consistent with previous in vitro work that showed the GABAergic neurons did not have shorter spikes than and glutamatergic neurons in the IC (Ono et al., 2005). Interestingly, the finding in IC is similar to that in the several hindbrain nuclei (Uusisaari et al., 2007; Bal et al., 2009; Saito et al., 2015). Thus, fast spiking is not a universal marker for GABAergic neurons, although in the IC, it may be relevant to some subtypes of glutamatergic or GABAergic neurons (Ono et al., 2005; Ito et al., 2009). 
GABAergic neurons had higher spontaneous firing rates than glutamatergic neurons

We found that the GABAergic neurons in the IC had higher firing rates than glutamatergic neurons. This result is consistent with a previous study that reported the inhibitory spontaneous synaptic inputs were more frequent than the excitatory spontaneous synaptic inputs in the IC (Ono and Oliver, 2014a). GABAergic neurons in the IC may contribute local axons (Winer et al., 1996; Ito et al., 2009), and spontaneous firing by the IC GABAergic neurons might provide an inhibitory background activity. This could contribute to gain control (Mitchell and Silver, 2003; Sivaramakrishnan et al., 2004) or stabilize the network neuronal activity (Isaacson and Scanziani, 2011). In the neocortex, parvalbuminpositive GABAergic neurons have higher spontaneous firing rates than glutamatergic pyramidal neurons (Liu et al., 2009; Moore and Wehr, 2013; Mesik et al., 2015). However, in contrast to the neocortex, the GABAergic neurons in the IC did not have higher firing rates evoked by sound. This might reflect the absence of fast-spiking neurons in the IC.

\section{Spatial organization may impose common response properties on GABAergic and glutamatergic IC neurons}

With most measures, the mean response of the GABAergic and glutamatergic neurons did not differ significantly. IC neurons have diverse responses to pure tones and AM sounds (Rees et al., 1997; Joris et al., 2004). Consistent with previous reports in the mouse IC (Ehret and Moffat, 1985; Walton et al., 2002), we observed diverse PSTHs, rMTFs, and tMTFs in both GABAergic and glutamatergic neurons.

The circuitry of the IC may impose some common response properties on both cell classes. In the ICC, both classes contribute to the formation of the fibrodendritic laminae (Oliver et al., 1994), the basis of the tonotopic organization in the ICC. This is consistent with the finding that nearby neurons shared similar FRAs, regardless of their cell types (Fig. 4). Thus, both cell classes within a fibrodendritic lamina may share inputs with similar tuning and be part of the same local circuit.

In addition to the laminar structure, the IC may have larger functional zones, synaptic domains, that receive their afferent inputs from a specific subset of lower auditory nuclei (Oliver, 2000; Loftus et al., 2010; Choy Buentello et al., 2015; Ono and Ito, 2015). Thus, the location of a neuron within the IC may be an important determining factor in its responses to sound. In our data, the $\mathrm{CF}$ and spike latency were correlated with the recording depth (Fig. 2C,D). Also, maximum firing rate and BW40 were affected by the location in the IC (Fig. 8). However, these parameters were not different between GABAergic and glutamatergic neurons. When we examined the response characteristics of nearby neurons (Figs. 4, 5B), we found that the neurons in the same local circuit shared similar frequency tuning (Fig. 4) but not temporal firing patterns (Fig. 5B). This is consistent with previous work using tetrode recordings (Seshagiri and Delgutte, 2007; Chen et al., 2012). IC neurons that are in adjacent fibrodendritic laminae may receive synaptic inputs with different temporal properties from different sources (Ono and Oliver, 2014a), despite having very similar BFs (Oliver, 2000). These may yield nearby neurons with different PSTHs and temporal patterns. Again, this relationship between local neurons was observed regardless of the cell type.

These results were in contrast to the sensory cortices. In sensory cortices, the interneurons have been reported to have different receptive fields and tuning properties from pyramidal neurons (Andermann et al., 2004; Sohya et al., 2007; Niell and
Stryker, 2008; Liu et al., 2009; Mesik et al., 2015). Especially, parvalbumin-positive neurons, the most studied subtype of cortical interneurons, have been reported to have a broader tuning property than pyramidal neurons (Kerlin et al., 2010; Ma et al., 2010; Mesik et al., 2015; but see Runyan et al., 2010; Moore and Wehr, 2013), and hypothesized to reflect pooled activity in the local excitatory neurons (Kerlin et al., 2010; Moore and Wehr, 2013). Although we could not distinguish the GABAergic subpopulations in our data, it is possible that some subtypes might have distinct properties as in the sensory neocortex. In the IC, both GABAergic and glutamatergic neurons have morphological and physiological subtypes (Sivaramakrishnan and Oliver, 2001; Ono et al., 2005; Tan et al., 2007; Ito et al., 2009; Beebe et al., 2016). Among them, the large tectothalamic projecting GABAergic neurons have a unique morphological structure with dense axosomatic excitatory inputs that are not seen in other GABAergic or glutamatergic neurons (Ito et al., 2009; Ito and Oliver, 2014; Beebe et al., 2016). These differences in their synaptic structures are likely to affect their responses to sound and might form distinct populations with specific sound response features.

Glutamatergic neurons also have subpopulations. Our data showed that the glutamatergic neurons with strong monotonicity had a significantly smaller dynamic range for sound intensity and firing rate in their RLFs than other groups (Fig. 2G,H). Such neurons with strong monotonicity might correspond to some physiological and/or morphological subset (Sivaramakrishnan and Oliver, 2001).

\section{Temporal properties may distinguish GABAergic neurons}

In the auditory system, the IC is a turning point in temporal coding. In the auditory brainstem, specialized neurons transmit temporal information with high precision, but in the IC temporal information is degraded (Joris et al., 2004). Fewer neurons are able to follow fast temporal changes in the auditory signal in the IC than in the brainstem, perhaps due to slower membrane properties in the IC neurons (Ono and Ito, 2015). Some differences in temporal properties were found between GABAergic and glutamatergic neurons. No GABAergic neurons had high-pass rMTFs to SAM tones and fewer were synchronized to high modulation frequencies with sharp raised sine envelopes (Figs. 6, 7). These differences might reflect different membrane properties in these cell classes. A previous report showed that the GABAergic neurons had strong long-duration afterhyperpolarizations (Ono et al., 2005). In addition, they had an overall slower membrane time constant than the glutamatergic neurons (Ono et al., 2005). These membrane characteristics might prevent GABAergic neurons from following synaptic inputs evoked by fast amplitude modulations (Geis and Borst, 2009).

\section{References}

Andermann ML, Ritt J, Neimark MA, Moore CI (2004) Neural correlates of vibrissa resonance: band-pass and somatotopic representation of highfrequency stimuli. Neuron 42:451-463. CrossRef Medline

Bal R, Baydas G, Naziroglu M (2009) Electrophysiological properties of ventral cochlear nucleus neurons of the dog. Hear Res 256:93-103. CrossRef Medline

Beebe NL, Young JW, Mellott JG, Schofield BR (2016) Extracellular molecular markers and soma size of inhibitory neurons: evidence for four subtypes of GABAergic cells in the inferior colliculus. J Neurosci 36:39883999. CrossRef Medline

Bernstein LR, Trahiotis C (2010) Accounting quantitatively for sensitivity to envelope-based interaural temporal disparities at high frequencies. J Acoust Soc Am 128:1224-1234. CrossRef Medline

Carandini M, Heeger DJ (2011) Normalization as a canonical neural computation. Nat Rev Neurosci 13:51-62. CrossRef Medline 
Carney LH, Kim DO, Kuwada S (2016) Speech coding in the midbrain: effects of sensorineural hearing loss. Adv Exp Med Biol 894:427-435. CrossRef Medline

Chen C, Rodriguez FC, Read HL, Escabí MA (2012) Spectrotemporal sound preferences of neighboring inferior colliculus neurons: implications for local circuitry and processing. Front Neural Circuits 6:62. CrossRef Medline

Choy Buentello D, Bishop DC, Oliver DL (2015) Differential distribution of GABA and glycine terminals in the inferior colliculus of rat and mouse. J Comp Neurol 523:2683-2697. CrossRef Medline

Csicsvari J, Hirase H, Czurkó A, Mamiya A, Buzsáki G (1999) Oscillatory coupling of hippocampal pyramidal cells and interneurons in the behaving Rat. J Neurosci 19:274-287. Medline

Ding S, Wei W, Zhou FM (2011) Molecular and functional differences in voltage-activated sodium currents between GABA projection neurons and dopamine neurons in the substantia nigra. J Neurophysiol 106:30193034. CrossRef Medline

Egorova M, Ehret G, Vartanian I, Esser KH (2001) Frequency response areas of neurons in the mouse inferior colliculus: I. Threshold and tuning characteristics. Exp Brain Res 140:145-161. CrossRef Medline

Ehret G, Moffat AJ (1985) Inferior colliculus of the house mouse: II. Single unit responses to tones, noise and tone-noise combinations as a function of sound intensity. J Comp Neurol 156:619-635.

Escabí MA, Higgins NC, Galaburda AM, Rosen GD, Read HL (2007) Early cortical damage in rat somatosensory cortex alters acoustic feature representation in primary auditory cortex. Neuroscience 150:970-983. CrossRef Medline

Geis HR, Borst JG (2009) Intracellular responses of neurons in the mouse inferior colliculus to sinusoidal amplitude-modulated tones. J Neurophysiol 101:2002-2016. CrossRef Medline

Gittelman JX, Li N, Pollak GD (2009) Mechanisms underlying directional selectivity for frequency-modulated sweeps in the inferior colliculus revealed by in vivo whole-cell recordings. J Neurosci 29:13030-13041. CrossRef Medline

Gonzalez-Sulser A, Parthier D, Candela A, McClure C, Pastoll H, Garden D, Sürmeli G, Nolan MF (2014) GABAergic projections from the medial septum selectively inhibit interneurons in the medial entorhinal cortex. J Neurosci 34:16739-16743. CrossRef Medline

Henze DA, Borhegyi Z, Csicsvari J, Mamiya A, Harris KD, Buzsáki G (2000) Intracellular features predicted by extracellular recordings in the hippocampus in vivo. J Neurophysiol 84:390-400. Medline

Isaacson JS, Scanziani M (2011) How inhibition shapes cortical activity. Neuron 72:231-243. CrossRef Medline

Ito T, Oliver DL (2014) Local and commissural IC neurons make axosomatic inputs on large GABAergic tectothalamic neurons. J Comp Neurol 522:3539-3554. CrossRef Medline

Ito T, Bishop DC, Oliver DL (2009) Two classes of GABAergic neurons in the inferior colliculus. J Neurosci 29:13860-13869. CrossRef Medline

Joris PX, Schreiner CE, Rees A (2004) Neural processing of amplitudemodulated sounds. Physiol Rev 84:541-577. CrossRef Medline

Kerlin AM, Andermann ML, Berezovskii VK, Reid RC (2010) Broadly tuned response properties of diverse inhibitory neuron subtypes in mouse visual cortex. Neuron 67:858-871. CrossRef Medline

Kuo RI, Wu GK (2012) The generation of direction selectivity in the auditory system. Neuron 73:1016-1027. CrossRef Medline

Lee CM, Osman AF, Volgushev M, Escabí MA, Read HL (2016) Neural spike-timing patterns vary with sound shape and periodicity in three auditory cortical fields. J Neurophysiol 115:1886-1904. CrossRef Medline

Li N, Pollak GD (2013) Circuits that innervate excitatory-inhibitory cells in the inferior colliculus obtained with in vivo whole cell recordings. J Neurosci 33:6367-6379. CrossRef Medline

Liu BH, Li P, Li YT, Sun YJ, Yanagawa Y, Obata K, Zhang LI, Tao HW (2009) Visual receptive field structure of cortical inhibitory neurons revealed by two-photon imaging guided recording. J Neurosci 29:10520-10532. CrossRef Medline

Loftus WC, Bishop DC, Oliver DL (2010) Differential patterns of inputs create functional zones in central nucleus of inferior colliculus. J Neurosci 30:13396-13408. CrossRef Medline

Ma WP, Liu BH, Li YT, Huang ZJ, Zhang LI, Tao HW (2010) Visual representations by cortical somatostatin inhibitory neurons-selective but with weak and delayed responses. J Neurosci 30:14371-14379. CrossRef Medline
Merchán M, Aguilar LA, Lopez-Poveda EA, Malmierca MS (2005) The inferior colliculus of the rat: quantitative immunocytochemical study of GABA and glycine. Neuroscience 136:907-925. CrossRef Medline

Mesik L, Ma WP, Li LY, Ibrahim LA, Huang ZJ, Zhang LI, Tao HW (2015) Functional response properties of VIP-expressing inhibitory neurons in mouse visual and auditory cortex. Front Neural Circuits 9:22. CrossRef Medline

Mitchell SJ, Silver RA (2003) Shunting inhibition modulates neuronal gain during synaptic excitation. Neuron 38:433-445. CrossRef Medline

Moore AK, Wehr M (2013) Parvalbumin-expressing inhibitory interneurons in auditory cortex are well-tuned for frequency. J Neurosci 33: 13713-13723. CrossRef Medline

Niell CM, Stryker MP (2008) Highly selective receptive fields in mouse visual cortex. J Neurosci 28:7520-7536. CrossRef Medline

Oliver DL (2000) Ascending efferent projections of the superior olivary complex. Microsc Res Tech 51:355-363. CrossRef Medline

Oliver DL, Winer JA, Beckius GE, Saint Marie RL (1994) Morphology of GABAergic neurons in the inferior colliculus of the cat. J Comp Neurol 340:27-42. CrossRef Medline

Ono M, Ito T (2015) Functional organization of the mammalian auditory midbrain. J Physiol Sci 65:499-506. CrossRef Medline

Ono M, Oliver DL (2014a) Asymmetric temporal interactions of soundevoked excitatory and inhibitory inputs in the mouse auditory midbrain. J Physiol 592:3647-3669. CrossRef Medline

Ono M, Oliver DL (2014b) The balance of excitatory and inhibitory synaptic inputs for coding sound location. J Neurosci 34:3779-3792. CrossRef Medline

Ono M, Yanagawa Y, Koyano K (2005) GABAergic neurons in inferior colliculus of the GAD67-GFP knock-in mouse: electrophysiological and morphological properties. Neurosci Res 51:475-492. CrossRef Medline

Ono M, Bishop DC, Oliver DL (2016) Long-lasting sound-evoked afterdischarge in the auditory midbrain. Sci Rep 6:20757. CrossRef Medline

Pollak GD, Xie R, Gittelman JX, Andoni S, Li N (2011) The dominance of inhibition in the inferior colliculus. Hear Res 274:27-39. CrossRef Medline

Portfors CV, Roberts PD (2014) Mismatch of structural and functional tonotopy for natural sounds in the auditory midbrain. Neuroscience 258: 192-203. CrossRef Medline

Ramachandran R, Davis KA, May BJ (1999) Single-unit responses in the inferior colliculus of decerebrate cats: I. Classification based on frequency response maps. J Neurophysiol 82:152-163. Medline

Rees A, Sarbaz A, Malmierca MS, Le Beau FE (1997) Regularity of firing of neurons in the inferior colliculus. J Neurophysiol 77:2945-2965. Medline

Romand R, Ehret G (1990) Development of tonotopy in the inferior colliculus: I. Electrophysiological mapping in house mice. Brain Res Dev Brain Res 54:221-234. CrossRef Medline

Runyan CA, Schummers J, Van Wart A, Kuhlman SJ, Wilson NR, Huang ZJ, Sur M (2010) Response features of parvalbumin-expressing interneurons suggest precise roles for subtypes of inhibition in visual cortex. Neuron 67:847-857. CrossRef Medline

Saito Y, Zhang Y, Yanagawa Y (2015) Electrophysiological and morphological properties of neurons in the prepositus hypoglossi nucleus that express both ChAT and VGAT in a double-transgenic rat model. Eur J Neurosci 41:1036-1048. CrossRef Medline

Sato TK, Haider B, Häusser M, Carandini M (2016) An excitatory basis for divisive normalization in visual cortex. Nat Neurosci 19:568-570. CrossRef Medline

Seshagiri CV, Delgutte B (2007) Response properties of neighboring neurons in the auditory midbrain for pure-tone stimulation: a tetrode study. J Neurophysiol 98:2058-2073. CrossRef Medline

Sivaramakrishnan S, Oliver DL (2001) Distinct K currents result in physiologically distinct cell types in the inferior colliculus of the rat. J Neurosci 21:2861-2877. Medline

Sivaramakrishnan S, Sterbing-D'Angelo SJ, Filipovic B, D'Angelo WR, Oliver DL, Kuwada S (2004) GABA(A) synapses shape neuronal responses to sound intensity in the inferior colliculus. J Neurosci 24:5031-5043. CrossRef Medline

Sohya K, Kameyama K, Yanagawa Y, Obata K, Tsumoto T (2007) GABAergic neurons are less selective to stimulus orientation than excitatory neurons in layer II/III of visual cortex, as revealed by in vivo functional $\mathrm{Ca}^{2+}$ imaging in transgenic mice. J Neurosci 27:2145-2149. CrossRef Medline 
Sosulina L, Graebenitz S, Pape HC (2010) GABAergic interneurons in the mouse lateral amygdala: a classification study. J Neurophysiol 104:617626. CrossRef Medline

Tan ML, Theeuwes HP, Feenstra L, Borst JG (2007) Membrane properties and firing patterns of inferior colliculus neurons: an in vivo patch-clamp study in rodents. J Neurophysiol 98:443-453. CrossRef Medline

Uusisaari M, Obata K, Knöpfel T (2007) Morphological and electrophysiological properties of GABAergic and non-GABAergic cells in the deep cerebellar nuclei. J Neurophysiol 97:901-911. CrossRef Medline

van Vreeswijk C, Sompolinsky H (1996) Chaos in neuronal networks with balanced excitatory and inhibitory activity. Science 274:1724-1726. CrossRef Medline

Walton JP, Simon H, Frisina RD (2002) Age-related alterations in the neural coding of envelope periodicities. J Neurophysiol 88:565-578. Medline

Watkins PV, Barbour DL (2011) Rate-level responses in awake marmoset auditory cortex. Hear Res 275:30-42. CrossRef Medline

Wehr M, Zador AM (2003) Balanced inhibition underlies tuning and sharpens spike timing in auditory cortex. Nature 426:442-446. CrossRef Medline

Winer JA, Saint Marie RL, Larue DT, Oliver DL (1996) GABAergic feedfor- ward projections from the inferior colliculus to the medial geniculate body. Proc Natl Acad Sci U S A 93:8005-8010. CrossRef Medline

Wu GK, Li P, Tao HW, Zhang LI (2006) Nonmonotonic synaptic excitation and imbalanced inhibition underlying cortical intensity tuning. Neuron 52:705-715. CrossRef Medline

Xiong XR, Liang F, Li H, Mesik L, Zhang KK, Polley DB, Tao HW, Xiao Z, Zhang LI (2013) Interaural level difference-dependent gain control and synaptic scaling underlying binaural computation. Neuron 79:738-753. CrossRef Medline

Zhao S, Ting JT, Atallah HE, Qiu L, Tan J, Gloss B, Augustine GJ, Deisseroth K, Luo M, Graybiel AM, Feng G (2011) Cell type-specific channelrhodopsin-2 transgenic mice for optogenetic dissection of neural circuitry function. Nat Methods 8:745-752. CrossRef Medline

Zheng Y, Escabí MA (2008) Distinct roles for onset and sustained activity in the neuronal code for temporal periodicity and acoustic envelope shape. J Neurosci 28:14230-14244. CrossRef Medline

Zheng Y, Escabí MA (2013) Proportional spike-timing precision and firing reliability underlie efficient temporal processing of periodicity and envelope shape cues. J Neurophysiol 110:587-606. CrossRef Medline 